\title{
Statistical analysis of the Mesoscale convective systems propagation east of the Rocky Mountains
}

\author{
Yunsung Hwang • Yanping Li
}

Received: date / Accepted: date

\begin{abstract}
In this work, we characterized the occurrences and propagation speeds of Mesoscale Convective Systems (MCSs) east of the Rocky Mountains, using 15 years of radar data. The central United States has a complex topography. The region also has atmospheric environments that initiate and maintain MCSs at multiple scales. The diurnal and regional variability of MCSs based on their longevities was obtained using high-resolution observation data (Stage IV) and an object tracking algorithm MODE-Time Domain (MTD). MTD-determined MCSs in spring and summer were divided into daytime (initiated from 12 to 23 UTC, MCS12) and nighttime MCSs (formed between 00 and 11 UTC, MCS00) and into short lived (less than the $75^{\text {th }}$ percentile) and long lived MCSs (greater or equal to the $75^{\text {th }}$ percentile). Propagation speeds of MCSs were calculated using distances between MCSs' centroids at each time step. We suggest a novel way to obtain a Hovmoller diagram to indicate average propagation speeds. There were two key results: 1) Spatial and temporal features of propagation speeds vary at each location and time and, 2.) heavy rainfall (rain rates $\geq 5.0 \mathrm{mmhr}^{-1}$ ) contributed more than lighter rainfall to overall precipitation. In the east during spring, longlived MCSs occurred more frequently in the spring than in summer. Short-lived daytime MCSs in spring and summer exhibited similar spatial distributions. In summer alone, short-lived nighttime MCSs occurred more frequently that they did in spring. To the east, the average propagation speeds of short-lived MCSs increased in spring and summer, whereas long-lived MCSs indicated decreasing trends.
\end{abstract}

Keywords Mesoscale Convective Systems (MCSs) - Propagation speeds of MCSs · Occurrences of MCSs

Yunsung Hwang

Global Institute for Water Security at the University of Saskatchewan, 11 Innovation Blvd, Saskatoon, SK, S7N 3H5, Canada

E-mail: hisnameys@gmail.com

Yanping Li

Global Institute for Water Security at the University of Saskatchewan, 11 Innovation Blvd, Saskatoon, SK, S7N 3H5, Canada

E-mail: yanping.li@usask.ca 


\section{Introduction}

Deep moist convection is important for its role in energy transfer in circulation (Glickman, 2000). Convective storms can generate severe weather systems by offering vertically developed columns of free convection. Mesoscale Convective Systems (MCSs) are defined as organized convections and as continuous thunderstorms associated with precipitation greater than $100 \mathrm{~km}$ in at least one horizontal direction (Houze, 1993). Known for their persistence, MCSs can linger for several hours or more. MSCs can be useful to farmers because they are the source of rainfall (Fritsch et al., 1986; Jirak et al., 2003; Ashley et al., 2003). However, they can also be hazardous as they can be accompanied by severe localized winds, damaging hail, flash flooding, and tornadoes (Maddox, 1980; Houze Jr et al., 1990; Trapp and Weisman, 2003; Jirak and Cotton, 2007). Regardless of whether their impacts are beneficial or harmful, knowledge of MSCs' development in the United States is required for several reasons: First, MCSs contribute substantial precipitation to the hydrological cycle in the warm season in the contiguous United States (Carbone et al., 2002; Trier et al., 2010; Feng et al., 2019). MCSs account for 30 to $70 \%$ of the total warm-season precipitation in the central United States (Feng et al., 2016; Haberlie and Ashley, 2019; Feng et al., 2019). Second, in the central United States, MCS-contributed precipitation has increased both in amount and frequency in the last 35 years (Feng et al., 2019).

MCSs are commonly initiated by frontal boundaries that provide a kinematic lift of the air parcel over the central United States during the warm season. However, long-lived MCSs require additional features that support their development and organization. Authors indicate that one of these features is the strength of the vertical mean wind $(0-6 \mathrm{~km})$ impacting cold pool development, which maintains MCSs (Evans and Doswell, 2001). They also show that instabilities (i.e., Convective Available Potential Energy, CAPE) and wind shear can provide additional energy for long-lived MCSs. The authors used vertical mean wind and the existence of a cold pool to predict MCS propagation. Other authors have presented key parameters that enable MCSs to develop upscale growth to become MCSs: 1) low-level warm air advection, 2) low-level vertical wind shear, and 3) convective instability (Corfidi, 2003; Jirak and Cotton, 2007). Another study (Coniglio and Corfidi, 2006) focuses on the propagation speed and longevity of MCSs. They used 348 warm-season MCS proximity soundings from a variety of MCS types to develop a parameter. Tested in the summer of 2005, the parameter shows promising results.

During the day, diabatic heating from the surface can overcome the inversion layer (or Convective Inhibition, CIN) formed before sunrise. Radiative heating can warm the air parcel near the ground, causing it to ascend freely even when there is an inversion layer (Grabowski et al., 2006). Nighttime convection has different mechanisms because no heat sources exist after sunset. A series of studies has suggested the Rocky Mountains as a source region, which has feedback without diabatic heating (i.e., lack of surface-based CAPE) (Heideman and Michael Fritsch, 1988; Tripoli and Cotton, 1989a,b). The authors suggest that advected warm air (during the day) from the west can act as an elevated heat source to maintain the convection (Tripoli and Cotton, 1989a,b). At least one study indicates that eastward propagating gravity waves developed over the elevated terrain (the Rocky Mountains) can trigger convections at night over the plains. When convection is 
triggered, the system maintains itself by obtaining energy sources from latent heat released in emerging MCSs (Tuttle and Davis, 2006; Trier et al., 2010). Other studies have discovered that a southerly Low Level Jet (LLJ) impacts nighttime MCS development and maintenance (Arritt et al., 1997; Pu and Dickinson, 2014).

The spatial and temporal characteristics of MCSs in the central United States in the warm season have been determined and documented in previous studies (Feng et al., 2019; Song et al., 2019). MCSs occur more frequently under strong baroclinic forcing in spring and fall while MCSs are initiated in weaker conditions in summer (Feng et al., 2019). Song et al. (2019) also indicate that high CAPE and negative CIN are required for convection in spring, while relatively low CAPE and CIN are observed in summer based on a 13-year study using radar data and the North American Regional Reanalysis (NARR). Another previous study points out that from spring to fall, LLJ transfers warm moist air from the south (Feng et al., 2019). Moreover, nocturnal LLJ occurs more frequently east of the Rocky Mountains in late spring and summer (Geerts et al., 2017) than in other seasons. Note that the locations of MCS development overlap in places where LLJ has occurred (Arritt et al., 1997; Geerts et al., 2017).

The purpose of this study is to characterize the occurrences and propagations of MCS in the central United States. Warm-season extreme precipitation events, many associated with MCSs, have been studied for several decades all over the world (Laing and Fritsch, 2000), including east of the Rocky Mountains (Heideman and Michael Fritsch, 1988; Tripoli and Cotton, 1989a,b; Li and Smith, 2010; Feng et al., 2019). Using observational data, researchers have improved understanding of synoptic conditions, convection initiation (Jirak and Cotton, 2007; Coniglio and Corfidi, 2006; Geerts et al., 2017), and Numerical Weather Prediction model simulations (Pu and Dickinson, 2014; Feng et al., 2019). However, the results are limited to intense and long-lived MCSs (Feng et al., 2016, 2019) or are based on the overall longevity of MCSs (Carbone et al., 2002; Carbone and Tuttle, 2008). At least one study, based on five years of observational data, has shown that nighttime MCSs occur most frequently in July (Geerts et al., 2017). Recent studies have divided MCSs in the United States into two sub-daily categories (six- and eight-hourly) to indicate differences (Prein et al., 2017; Haberlie and Ashley, 2019). However, subdaily features of MCSs may include features from both daytime- and nighttimeinitiated MCSs. Additionally, the individual contributions of long- and short-lived MCSs are not understood, and the research focus has been more on long-lived MCSs. Our goal is to fill this gap of understanding by categorizing MCSs based on whether they are short or long lived and occur in the daytime or nighttime. The findings will help researchers understand the characteristics of MCSs by providing detailed information about short-/long-lived and daytime/nighttime MCSs.

The description datasets and a technique to analyze and to identify and track MCSs are described in section 2. The characteristics of MCSs in the analysis region are discussed in section 3. Finally, a summary and discussion are provided in section 4. 


\section{Data and methodology}

\subsection{Data}

In this study, observed precipitation systems were used to characterize MCSs in the central United States. We used fifteen years of hourly data (from 2004 to 2018) from radar networks. The analysis domain was chosen to include the complex terrain and initiation of MCSs east of the Rocky Mountains, as shown in Fig. 1.

\subsubsection{Stage IV data}

Stage IV Quantitative Precipitation Estimates (QPE) are a 4-km grid-size product of mosaic in hourly, 6-hourly, and daily accumulation provided to the public and maintained by the National Centers for Environmental Prediction (NCEP). Historically, Stage IV data were incorporated into data assimilation. However, the advantages of high temporal and spatial resolution of data enabled their further use to accurately measure precipitation and to compare these measurements to ground station-, radar-, and satellite-based algorithms (Nelson et al., 2016). Some studies have compared the precipitation systems from observational data and Regional Climate Model (RCM) simulations (Prein et al., 2017; Scaff et al., 2019).

\subsection{Methodology}

\subsubsection{MODE Time Domain (MTD)}

Model Evaluation Tools (MET) were developed by Developmental Testbed Center (DTC, https://dtcenter.org). MET includes the Method for Object-Based Diagnostic Evaluation (MODE) used in the evaluation of model results with observations (Cai and Dumais Jr, 2015). MODE-Time Domain (MTD), part of MODE, was used to further define and track the objects based on modules in MODE. The procedures of MTD are as follows:

1) convoluting (dilating/smoothing) objects with user-defined smoothing length (conv_radius $=8$ pixels, $32 \mathrm{~km}$ ).

2) defining objects with a user-defined threshold (conv_thresh=5.0 $\mathrm{mmhr}^{-1}$ ).

3) identifying and numbering contiguous objects in the time domain, considering the minimum three-dimensional object size (i.e., latitude, longitude, and time), while the minimum size is predefined by a user (min_volume $=2000$ ).

The precipitation systems determined by MTD are sensitive to the set-up values in a configuration as "conv_radius", "conv_thresh", and "min_volume". When the smoothing radius and threshold are set to larger values, only a few objects are remained by smoothing and thresholds (Prein et al., 2017). In this study, the configuration is designed to detect MCSs related to extreme precipitation systems.

\subsubsection{Hovmoller diagram}

A Hovmoller diagram is a method to plot meteorological data to highlight the role of wave-like features. The data are shown as axes of longitude or latitude (abscissa or $\mathrm{x}$-axis) and time (ordinate or $\mathrm{y}$-axis). The values are indicated as shadings 
to emphasize features propagating in the east-west or south-north direction with respect to time. In this study, the propagation of a precipitation system is represented as a Hovmoller diagram to indicate longitudinal movement with time. The method to obtain representative occurrences in the longitude uses equations as:

$$
\begin{aligned}
\operatorname{OCC}(t, i)= & \sum_{j=1}^{j=m} \operatorname{Freq}\left[\operatorname{RR}(t, i, j) \geq 5.0 \mathrm{mmhr}^{-1}\right] \\
& t=\text { time in UTC (00 to } 23) \\
& i=1 \ldots \mathrm{m}, \text { index of Longitude (i.e., west to east) } \\
& j=1 \ldots \mathrm{n}, \text { index of Latitude (i.e., south to north). }
\end{aligned}
$$

while $R R$ is the rain rate in $\mathrm{mmhr}^{-1}$ in three dimensions in time, latitude, and longitude. Using this method, (OCC in (1)), we obtained the occurrences of rain rates over $5.0 \mathrm{mmhr}^{-1}$ at each location. In this study, we obtained twodimensional 24-hour accumulated occurrences of $\mathrm{RR} \geq 5.0 \mathrm{mmhr}^{-1}$ to show the spatial distributions in the analysis region. In this way, we obtained characteristics in both Hovmoller diagrams (no information from latitudinal dimension) and spatial distributions (time dimension removed).

Propagation speeds of MCSs We propose a novel way to obtain a Hovmoller diagram of the propagation speeds of MCSs to represent their longitudinal movement. First, the propagation speeds were assigned to MTD-determined objects. At each time step, the propagation speed was estimated by the movement of centroids (the Euclidean distance of an object at the time and the previous time). The latter object has a uniform propagation speed considering the distances from the previous location. The propagation speeds were averaged in the analysis region as follows:

$$
\begin{aligned}
\operatorname{AVGspd}(t, i) & =\frac{\sum_{j=1}^{j=m} \operatorname{Spd}(t, i, j)}{\operatorname{OCC}(t, i)} \\
t & =\text { time in UTC }(00 \text { to } 23) \\
i & =1 \ldots \mathrm{m}, \text { index of Longitude (i.e., west to east) } \\
j & =1 \ldots \mathrm{n}, \text { index of Latitude (i.e., south to north). }
\end{aligned}
$$

Note that $\operatorname{Spd}(t, i, j)$ is an average propagation speed in time, longitude, and latitude. The Hovmoller diagram of propagation speed considers only the objects including $\mathrm{RR}(t, i, j) \geq 5.0 \mathrm{mmhr}^{-1}$. We chose to obtain the values of $A V G \operatorname{spd}(t, i)$ only for the $O C C(t, i) \geq \overline{O C C(t, i)}$ to exclude uncertainties of propagation speeds of low frequencies (i.e., the low confidence of the values of $\operatorname{AVGspd}(t, i, j)$ due to fewer events).

Statistics of MCSs We obtained areal-average values from MTD-determined objects to obtain the statistics as 1) propagation speeds, 2) areal coverages, 3) the E-W component of propagation, and 4) the N-S component of propagation. The average values of each MCS were obtained hourly to represent the lifecycles of MCSs. The MCSs were further divided into quantiles based on longevities in seasons. We 
defined short-lived MCSs as those with longevities under the $75^{\text {th }}$ percentile and long-lived MCSs as those with longevities of over the $75^{\text {th }}$ percentile. We defined MCSs as daytime if initiation was 12 to 23 UTC and nighttime if initiation was 00 to 11 UTC. Note that LST can be calculated by deducting 6 hours from UTC in the analysis region to have 18 to 05 LST for nighttime and 06 to 17 LST for daytime MCSs.

Features of frequencies and propagation speeds of MCSs in elevations We combined diurnal cycles of occurrences and propagation speeds of MCSs to represent features in elevations (i.e., by removing y-axis and thte time-domain from Hovmoller diagrams). For occurrences of MCSs, total frequencies were accumulated at each longitude (24-hour summation). For propagation speeds, we applied the temporal average of propagation speeds (24 hours) from Hovmoller diagrams. We obtained terrain heights by interpolating Geographical Static Data using the Weather Research and Forecasting Pre-Processing System (WPS) in the analysis region. Later, we obtained mean elevation heights at each longitude to indicate average elevations.

\section{Results}

\subsection{Occurrence of MCSs}

The average rain rates $(\mathrm{RR})$ and occurrences of $\mathrm{RR} \geq 5 \mathrm{mmhr}^{-1}$ in spring (MAM) and summer (JJA) over the central United States exhibited similarities in distribution. In both seasons, MCSs propagated east from the Rocky Mountains to the Great Plains, resulting in average RR over $0.15 \mathrm{mmhr}^{-1}$ (yellow to red shades) over the Great Plains (Figs. 2a,b). The propagations are represented in Hovmoller diagrams by obtaining diagonal signals in high average $\mathrm{RR}$ values (i.e., $0.1 \mathrm{mmhr}$ ${ }^{-1}$ ) from the east during early hours (i.e., 00 to 03 UTC) to the west during later hours (i.e., 12 to 15 UTC), as seen in Figs. 2d,e.

The distributions of average RR showed seasonal differences in detail. First, the values of average RR in MAM increased from $100^{\circ} \mathrm{W}$ and showed high values over $0.15 \mathrm{mmhr}^{-1}$ and decreased close to the Appalachian Mountains (Fig. 2a). The envelope of high values was high average RR from $102^{\circ} \mathrm{W}$ at $00 \mathrm{UTC}$ to the east as shown in Fig. 2d. In JJA, average RR increased from $105^{\circ} \mathrm{W}$ where the altitudes were above $1000 \mathrm{~m}$ (about $300 \mathrm{~km}$ to the west compared to that of RR in MAM), as represented in Fig. 2b. The Hovmoller diagram of JJA indicated an envelope from $105^{\circ} \mathrm{W}$ at $00 \mathrm{UTC}$ to the east (Fig. 2e). Second, the high values of average $\mathrm{RR}$ showed different distributions over the central United States. MAM showed one region of high average $\mathrm{RR}$ over the eastern borders of Oklahoma, Kansas to the east through Iowa, Missouri, Arkansas to Mississippi, Tennessee, Kentucky, and the northern part of Alabama (Fig. 2a). JJA had the highest average RR near the coastal area (eastern Texas, southern parts of Louisiana, Mississippi, Alabama, and Georgia), as shown in Fig. 2b. The second highest average RR was located in eastern Kansas close to the border of Missouri and Iowa (Fig. 2b). The differences (i.e., RR(JJA) - RR(MAM)) showed negative values where MAM was distributed the most (central Texas through Arkansas to Kentucky and Tennessee) and positive values where JJA dominated $\left(105\right.$ to $\left.100^{\circ} \mathrm{W}\right)$ and the coastal area 
around the Gulf of Mexico (Fig. 2c). The dominance of JJA was also represented in the Hovmoller diagram, which showed positive values around 105 to $100^{\circ} \mathrm{W}$ at 00 to $06 \mathrm{UTC}$ and negative values at $96^{\circ} \mathrm{W}$ from 00 to $15 \mathrm{UTC}$ (Fig. 2f). Note that occurrences of $\mathrm{RR} \geq 5 \mathrm{mmhr}^{-1}$ shared similar features of propagation with those of average RR, suggesting heavy rainfall contributed more than lighter rainfall to the high average RR. The distribution of occurrences of $R R \geq 5 \mathrm{mmhr}^{-1}$ were compared to the distribution of MTD-determined results to determine how the results are different.

\subsection{An example of a MTD determined MCS}

An example case was selected to demonstrate how MTD works and what the results of MTD look like. A case on 11 June 2007 was chosen with Synoptic and Mesoscale discussions. A tornado watch (\#378, https://www.spc.noaa.gov/products/md/ 2007/md1090.html) was issued, and a Storm Prediction Center (SPC) report represented tornado outbreaks in the central US (https://www.spc.noaa.gov/climo/ reports/070610_rpts.html). The synoptic weather regime associated with this case on 11 June 2007 was characterized by a mid-tropospheric short-wave trough moving east/northeastward from eastern Kansas /Oklahoma to western/central Missouri 0000 to 1200 UTC. There was a southerly LLJ kept moisture (dew point temperatures in the mid to upper $15^{\circ} \mathrm{C}$. This jet combined with the daytime heating to support $100 \mathrm{mb}$ Mixed Layer Convective Available Potential Energy, (MLCAPE) ranging from 2500 to $3000 \mathrm{Jkg}^{-1}$. At $2000 \mathrm{UTC}$, the low-level warm moist advection increased, and storms began to intensify. The storms had congealed into a MCS and propagated to the east at 0000 UTC 11 June. The results of MTD are provided in time from 0600 to 1200 UTC 11 June 2007 in Fig. 3. Rain rates are shown in filled contours, and red contours indicate MTD-determined objects. Note that a tornado watch was issued at 0600 UTC, and that MTD successfully captured the severe storms. The rain rates were extremely high, over 40 $\mathrm{mmhr}^{-1}$ (purple to white colors) throughout the time. It should be noted that MCS shrunk from 1500 to 1600 UTC, and the areal coverage decreased dramatically by losing the area on the border of Missouri and Arkansas.

\subsection{MTD determined MCSs}

The distributions of MTD-determined MCSs (MCS24) shared similarities with distributions of RR occurrences $\geq 5 \mathrm{mmhr}^{-1}$ (Fig. 2g and h); however, they exhibited differences in detail. The maximum values of MTD-determined MCSs were about $20 \mathrm{yr}^{-1}$ (Fig. 4), while RR $\geq 5 \mathrm{mmhr}^{-1}$ were close to $40 \mathrm{yr}^{-1}$ for MAM (Fig. 2g) and for JJA (Fig. 2h). The high values of occurrences of MCS24 in MAM (Fig. 4a) shifted to the south (roughly south of $37^{\circ} \mathrm{N}$ ) compared to those of $\mathrm{RR} \geq 5$ $\mathrm{mmhr}^{-1}$ (Fig. 2g). The high values of $\mathrm{RR} \geq 5 \mathrm{mmhr}^{-1}$ in central Missouri might not contribute to organized MCSs. Similarly, the high values of $R R \geq 5 \mathrm{mmhr}$ ${ }^{-1}\left(\right.$ over $\left.35 \mathrm{yr}^{-1}\right)$ in the southern coastal area in JJA (Fig. 2h) were not seen in MTD-determined MCSs, which had lower values of $20 \mathrm{yr}^{-1}$ (4b). This means that only $50 \%$ of events are determined by MTDs. The differences were clearly seen as positive values to the north (from Oklahoma to Illinois through Missouri), where 
MCSs were more frequent in JJA than in MAM (Fig. 4c). The negative values of occurrence showed MCSs in MAM occurred more often in the southern parts of the central US to the east (Fig. 4c). The features of daytime MCSs (MCS12) and nighttime MCSs (MCS00) contributed differently to the occurrences. Both MCS00 and MCS12 in MAM contributed similarly to MCS24 in MAM (Fig.4a). However, the locations of the highest values (over 100 count as dark reds) showed differences in MCS00 and MCS12 for MAM. The highest values of MCS00 MAM occurred near $35^{\circ} \mathrm{N}$, Missouri to the east (Fig. 4d), while MCS12 MAM occurred most often near $32^{\circ} \mathrm{N}$, in Louisiana, Mississippi, and the northern part of Alabama (Fig. $4 \mathrm{~g}$ ). The differences in contributions of MCS00 and MCS12 in JJA were clearer than those of MAM. MCS00 in JJA showed that the highest values were near the coastal areas (southeastern Texas, southern MississippI, and southern Alabama), and secondary high values were represented in eastern Oklahoma and Kansas to Minnesota (Fig. 4g). The higher values of MCS00 JJA covered most areas east of $100^{\circ} \mathrm{W}$ including Nebraska and central Missouri. On the other hand, MCS12 from JJA showed narrower coverage of high values compared to that of MCS00 JJA (Fig. 4h). MCS12 JJA showed high values from central Oklahoma and Kansas to the border of Iowa and Missouri, as well as in the coastal area of Louisiana and Mississippi (Fig. 4h). The Hovmoller diagrams of MCS24 share similarities with MAM in occurrences of $R R \geq 5 \mathrm{mmhr}^{-1}$ (Fig. $2 \mathrm{j}$ ) but differences in JJA(Fig. 2k). The biggest difference is the lack of high values in JJA from $93^{\circ} \mathrm{W}$ at 20 UTC to $87^{\circ} \mathrm{W}$ at 23 UTC (Fig. 2k) in MTD-determined MCS24. High value occurrences of $\mathrm{RR} \geq 5 \mathrm{mmhr}{ }^{-1}$ in the southern coastal area in JJA (Fig. 2h) showed only half of the events that occurred in MTD-determined MCSs (4b). Moreover, the high values of occurrence between -105 to $102^{\circ} \mathrm{W}$ (Fig. 2k) were not shown in MTD-determined MCSs (Fig. 5b). Thus, precipitation systems of RR $\geq 5 \mathrm{mmhr}$ ${ }^{-1}$ may not be able to organize or maintain MCSs. Note that the elevation in the region is over $1000 \mathrm{~m}$. Although any precipitation system can organize and maintain MCSs, these storms are not as easily maintained in higher elevations.

The features of MCS12 and MCS00 contributed differently to occurrences of MCSs in the Hovmoller diagrams. MCS00 organized envelopes in MAM and JJA (Fig. 5d, e). MCS00 in MAM had two envelopes of high occurrences from $99^{\circ} \mathrm{W}$ at $06 \mathrm{UTC}$ to $96^{\circ} \mathrm{W}$ at $18 \mathrm{UTC}$ and $96^{\circ} \mathrm{W}$ at $00 \mathrm{UTC}$ to $90^{\circ} \mathrm{W}$ at $12 \mathrm{UTC}$. MCS00 in JJA had an envelope of high occurrences from $102^{\circ} \mathrm{W}$ at $03 \mathrm{UTC}$ to $96^{\circ} \mathrm{W}$ at 16 UTC. The envelope of high occurrences of JJA had higher envelope speeds (propagating longer distances in the same amount of time) than those in MAM (Fig. 5d, e), and the coverages of MCS00 in JJA are larger than those in MCS00 MAM (4d,e). Note that MCS00 in JJA showed higher occurrences of over $200 \mathrm{yr}^{-1}$, while for MCS00 in MAM, the highest count was $180 \mathrm{yr}^{-1}$. MCS12 showed similar features in the occurrences in MAM and JJA (Fig. 5g, h). Both MCS12 in MAM and JJA showed multiple envelopes of high values (over $160 \mathrm{yr}^{-1}$ ). The highest occurrences occurred between 99 and $96^{\circ} \mathrm{W}$ around 23 to 06 UTC for MAM and 22 to 06 UTC for JJA (Fig. $5 \mathrm{~g}, \mathrm{~h}$ ). Note that the highest values of occurrences between 99 and $96^{\circ} \mathrm{W}$ were in eastern Texas to Oklahoma in MAM (Fig. 4g) and in Oklahoma to Kansas in JJA (Fig. 4h) for MCS12. 
3.4 Statistics of MTD determined MCSs

The distribution of longevities was divided into nighttime and daytime MCSs. Statistics for areal coverages, propagation speeds, and E-W and N-S components of MCSs are shown in Fig. 6. Long-lived MCSs were defined as having longevities greater or equal to the $75^{\text {th }}$ percentile of longevities in MAM and JJA (solid lines in Fig. 6). Short-lived MCSs were defined as having lifetimes that were less than the $75^{\text {th }}$ percentile of longevities. They are represented as dotted lines in Fig. 6 . The values of the $75^{\text {th }}$ percentile were 11 hours for both MAM and JJA for MCS00, 12 hours for MAM, and 10 hours for JJA for MCS12. The mean coverages of longlived MCSs showed values for both MCS00 and MCS12 in MAM that were twice as large as those in JJA (Fig. 6c,d), while short-lived MCSs did not show differences. Propagation speeds were no different in long-lived and short-lived MCSs; however, MCS00 in MAM revealed propagation speeds about $2 \mathrm{~ms}^{-1}$ higher than those in JJA (Fig. 6e). There were no clear differences between E-W and N-S propagation speeds, while MCS00 showed values about $2 \mathrm{~ms}^{-1}$ higher than those of MSC12. (Fig. 6g, i). Note that MTD-determined MCSs (both MCS00 and MCS12) showed mean propagation directions to the east (Fig. 6g, h) for both MAM and JJA. When N-S directions were considered, MCSs in MAM showed average directions to the north while those in JJA were to the south (Fig. 6i, j)

\subsection{Features of daytime / nighttime MCSs}

The features of short- and long-lived daytime (MCS12s, MCS12l) and nighttime MCSs (MCS00s, MCS001) showed differences in the extent to which they contributed to MCS occurrences. Long-lived MCSs in MAM and JJA contributed more than short-lived MCSs, as seen in Fig. 7. Only MCS00s in JJA showed significant contributions (over $5 \mathrm{yr}^{-1}$ ) in Oklahoma, Kansas, Nebraska, Missouri, and Iowa. MCS001 in JJA occurred frequently in eastern Oklahoma, Kansas, and Missouri but not in Nebraska., MCS00l in JJA also occurred frequently in South Dakota, North Dakota, and Minnesota, more to the east compared to MCS00s in JJA (Fig. 7b, e). Short-lived MCSs in MAM and JJA showed a broad distribution of high occurrences over $3 \mathrm{yr}^{-1}$, including in the northern part of the region (i.e., north of $40^{\circ} \mathrm{N}$ ), while long-lived MCSs showed high occurrences in concentrated regions. The features of short- and long-lived MCS12 and MCS00 contributed differently to occurrences of MCSs in the Hovmoller diagrams. Long-lived MCSs shared similarities with MCSs represented in Fig. 5 by occurring frequently at the same location and time. MCS00s from JJA contributed substantially to MCS occurrences (over $100 \mathrm{yr}^{-1}$ ) from $102^{\circ} \mathrm{W}$ at $03 \mathrm{UTC}$ to $96^{\circ} \mathrm{W}$ at $13 \mathrm{UTC}$ (Fig. $8 \mathrm{~b})$. MCS001 in JJA indicated high occurrences over $140 \mathrm{yr}^{-1}$ from $101^{\circ} \mathrm{W}$ at $06 \mathrm{UTC}$ to $95^{\circ} \mathrm{W}$ at $18 \mathrm{UTC}$ (Fig. $8 \mathrm{~b}$ ). The spatial differences can be seen in displacement of the high occurrences of MCS00s and MCS001 in JJA (Fig. 7b,e). Notably, long-lived MCSs in JJA may obtain enough energy to enable upscale growth and to propagate further to the east (Fig. 7e). The average propagation speeds of short- and long-lived daytime and nighttime MCSs showed spatial differences, as shown in Fig. 9. Short-lived MCSs in MAM and JJA did not show features related to occurrences of more than $2 \mathrm{yr}^{-1}$ (Fig. $9 \mathrm{a}, \mathrm{b}, \mathrm{e}, \mathrm{f}$ ). MCS00s in MAM showed propagation speeds of over $15 \mathrm{~ms}^{-1}$ in Kentucky, Indiana, and Ohio; 
however, there were fewer than $2 \mathrm{yr}^{-1}$ (i.e., less frequently occurrences). MCS001 in JJA exhibited increasing propagation speeds in the north, whereas MCSs near the coastal area showed propagation speeds of less than $8 \mathrm{~ms}^{-1}$ (Fig. 9d). Similar features were seen in MCS12l in JJA, which showed lower propagation speeds in the coastal areas and higher speeds in Iowa and to the northeast, as seen in Fig. 9h. The propagation speeds of MCS00l in MAM did not appear to be related to the occurrences of MCSs (no direct relationship between high propagation speeds and high occurrences). Note that long-lived MCSs in MAM showed higher average propagation speeds (over $8 \mathrm{~ms}^{-1}$ ) throughout the region (contours over 2 and 7 $\mathrm{yr}^{-1}$ ) both for daytime and nighttime MCSs as seen in Fig. 9c, g. The results agreed with MCSs in MAM showed higher propagation speeds than those in JJA in lifetimes of MCSs in Fig. 6e, f.

The propagation speeds of MCS12 and MCS00 are shown in the Hovmoller diagrams in Fig. 10. Short-lived MCSs in MAM and JJA did not show a clear relationship between high occurrences and high speeds of MCSs, except for MCS00s in JJA (Fig. 10b). MCS00s in JJA contributed significantly to the occurrences of $\mathrm{MCSs} 102^{\circ} \mathrm{W}$ at $03 \mathrm{UTC}$ to $96^{\circ} \mathrm{W}$ at $13 \mathrm{UTC}$ (Fig. 8b). The propagation speeds exhibited increasing values to higher occurrences (contours of occurrences $100 \mathrm{yr}^{-1}$ ), decreasing to the east of $96^{\circ} \mathrm{W}$ (Fig. 10b). MCS001 in MAM had two envelopes of high occurrences(contours of occurrences $100 \mathrm{yr}^{-1}$ ). The contours of occurrences over $100 \mathrm{yr}^{-1}$ in the east (from $99^{\circ} \mathrm{W}$ at $09 \mathrm{UTC}$ to $96^{\circ} \mathrm{W}$ at $18 \mathrm{UTC}$ ) and in the west (located from $96^{\circ} \mathrm{W}$ at $00 \mathrm{UTC}$ to $90^{\circ} \mathrm{W}$ at $12 \mathrm{UTC}$ ) indicated propagation speeds larger than $8 \mathrm{~ms}^{-1}$. MCS001 in JJA indicated high propagation speeds greater than $12 \mathrm{~ms}^{-1}$ and lower speeds to the east (from $102^{\circ} \mathrm{W}$ at 06 UTC to $96^{\circ} \mathrm{W}$ at $18 \mathrm{UTC}$ ), as shown in Fig. 10d. Similarly MCS12l in JJA showed high propagation speeds in the east $\left(-102\right.$ to $\left.-96^{\circ} \mathrm{W}\right)$ and the speed decreased to the east (lower than $8 \mathrm{~ms}^{-1}$ (in Fig. 10h).

\subsubsection{Features of MCSs based on elevation}

We obtained a summation of occurrences and average propagation speeds along the longitudes to compare with mean elevation at each longitude, as shown in Fig. 11. The results of average propagation speeds along the longitude showed increasing speeds from the west (to $99^{\circ} \mathrm{W}$ ) and the maintenance of speeds (about $10 \mathrm{~ms}^{-1}$ in MAM and $7.5 \mathrm{~ms}^{-1}$ in JJA) from 100 to $90^{\circ} \mathrm{W}$ for MCS00s in MAM and JJA. For MCS12s, MCSs in MAM showed higher (and increasing) propagation speeds of $2.5 \mathrm{~ms}^{-1}$ to the east of $99^{\circ} \mathrm{W}$, while propagation speeds of MCSs in JJA fluctuated along $8 \mathrm{~ms}^{-1}$ (Fig. 11e). In contrast, long-lived MCSs in MAM and JJA showed decreasing propagation speeds to the east, as shown in Fig. 11c and g.

The results of accumulated occurrences of MCSs showed peaks of high counts in the region of 99 to $93^{\circ} \mathrm{W}$ for MCS00s in MAM 100 to $98^{\circ} \mathrm{W}$ and in JJA (Fig. 11b). MCS00s in JJA occur about 2 times more frequently than in MAM 100 to $98^{\circ} \mathrm{W}$, as seen in Fig. $7 \mathrm{~b}$ and Fig. $8 \mathrm{~b}$. MCS12s in both MAM and JJA showed bell-shaped occurrences and peaks at $96^{\circ} \mathrm{W}$ (Fig. 11f). MCS001 in MAM and JJA indicated increasing occurrences at the peaks at $96^{\circ} \mathrm{W}$ but decreasing to the east (Fig. 11d). Notably, MCS00l in MAM occurred more often in the region from $96^{\circ} \mathrm{W}$ to the east, while MCS00l in JJA occurred less often from 92 to $90^{\circ} \mathrm{W}$. High occurrences of MCS001 in MAM were found more to the east, especially 
$90^{\circ} \mathrm{W}$ to the east (Fig. $7 \mathrm{~d}$ ). MCS12l in MAM showed the highest peak at $92^{\circ} \mathrm{W}$ and the second peak at $97^{\circ} \mathrm{W}$, wheras MCS12l in JJA peaks at the same location, as seen in Fig. 11h. The high occurrences of MCS12l in MAM and JJA occurred frequently in the coastal area (Mississippi to Alabama for MAM and southeastern Louisiana and Mississippi for JJA) (Fig. 7j, k).

\section{Summary and discussion}

\subsection{Discussion}

The regions that show high occurrences of $\mathrm{RR} \geq 5 \mathrm{mmhr}^{-1}$ showed agreement with the locations of high average RR (15 years), indicating that heavy rainfall contributed more than lighter rainfall to overall precipitation. Average RR in JJA occurred more frequently in elevations over $1000 \mathrm{~m}$ than did average RR in MAM. The distribution of regions with high $\mathrm{RR} \geq 5 \mathrm{mmhr}^{-1}$ was similar to that of high MTD-determined MCSs (i.e., MCS24). However, high occurrences of MCS24 in MAM shifted to the south compared to those of $\mathrm{RR} \geq 5 \mathrm{mmhr}^{-1}$. Additionally, fewer precipitation systems $\left(\mathrm{RR} \geq 5 \mathrm{mmhr}^{-1}\right)$ in the southern coastal area evolve to MCSs, as fewer objects (MCSs) are determined by MTD in JJA.

The results of spatial and temporal distributions of MCSs in this study showed agreement with previous studies. First, (Carbone et al., 2002,?) the Hovmoller diagrams represented east propagating precipitation systems over the central United States $\left(30\right.$ to $\left.48^{\circ} \mathrm{N}\right)$ based on radar data in the warm season (from May to August). The high frequencies of precipitation systems (i.e., propagation signals) were shown in the Hovmoller diagrams from $105^{\circ} \mathrm{W}$ at $20 \mathrm{UTC}$ to $95^{\circ} \mathrm{W}$ at $16 \mathrm{UTC}$ (Carbone et al., 2002; Carbone and Tuttle, 2008). Although we showed similar features as occurrences of RR $\geq 5.0 \mathrm{mmhr}^{-1}$ in JJA, the occurrences in JJA were shown from $105^{\circ} \mathrm{W}$ at $20 \mathrm{UTC}$ to $95^{\circ} \mathrm{W}$ at $15 \mathrm{UTC}$. MCS occurrences were missing from 20 to 00 UTC, possibly because of differences in the methodology we used to to obtain the precipitation systems. Second, features of MCSs and their precipitation in the United States for all seasons were studied using 22 years of radar data (Haberlie and Ashley, 2019). MCSs contributed $60 \%$ or more to the total precipitation in the warm season in Oklahoma and Kansas and from southwestern Nebraska to the border of Missouri and Iowa.

A previous study (Haberlie and Ashley, 2019) provided the contributions divided into 04-12, 12-20, 20-04 UTC and MCSs between 04 to 1200 UTC represented the higher contributions $(\geq 70 \%)$. Similar results were shown for nighttime long-lived MCSs in JJA. However, we think the features of daytime and nighttime MCSs may partially contribute to the previous study. The locations with high occurrences of MCSs agreed with the regions with LLJ in previous studies (Walters et al., 2008; Song et al., 2019; Feng et al., 2019). Although we did not show a direct relationship between high occurrences of MCSs and the existence of LLJ, the occurrences of MCSs showed similarities to the contributions to precipitation in previous studies (Feng et al., 2019).

Our propagation speed results were similar to those in previous studies. Average propagation speeds were 10 to $12.5 \mathrm{~ms}^{-1}$, and the highest values in spatial distributions and the Hovmoller diagrams were about $20 \mathrm{~ms}^{-1}$. (Carbone et al., 2002) showed average propagation speeds of $14 \mathrm{~ms}^{-1}$, with movements of at least 
$1000 \mathrm{~km}$ in 20-hour lifecycles. Additionally, our results showed agreement in the range of 12 to $14 \mathrm{~ms}^{-1}$ with ground station data (Li and Smith, 2010) and NWP simulation data (Scaff et al., 2019). The originality of the propagation in this study is that it shows average propagation speeds in spatial distributions and Hovmoller diagrams. The propagation speeds in spatial and temporal domains can provide additional information about features of MCSs, their acceleration, deceleration, along with occurrences. Additionally, to understand climatological characteristics of MCSs at specific locations and times, MCS can be categorized according to whether they occur in the daytime or nighttime and whether they are short or long lived MCSs.

\subsection{Summary}

In this work, we characterized the variability of MCSs east of the Rockies by statistical results using 10 years of observational data (stageIV) in spring and summer. The MCSs were identified and tracked by considering the areal coverages and temporal continuities using MTD (provided in MODE). Additionally, we calculated the propagation speeds of MCSs by obtaining the distances between centroids in identified MCSs at each time step (hourly). The occurrences of MCSs east of the Rockies, along with propagation speeds, were presented in spatial distributions and Hovmoller diagrams. The MCSs were divided into categories of daytime (initiated from 12 to 23 UTC, MCS12) and nighttime (formed in between 00 and 11 UTC, MCS00). To determine the factors that contribute to their occurrence, the MCSs were further divided into short- and long-lived categories based on longevities (the $75^{\text {th }}$ percentile of seasonal distributions MCS00: 12 hours for MAM, 10 hours for JJA, MCS12: 11 hours for MAM and JJA).

The key findings for the statistical features divided into short-/long-lived and daytime/nighttime MCSs are as follows: 1) long-lived MCSs in MAM showed mean areal coverages of twice the size of MCSs in JJA, 2) MCS00 in MAM showed 2 $\mathrm{ms}^{-1}$ higher propagation speeds than those in JJA, 3) MCSs in the warm season had east-propagation (E-W component), and 4) MAM showed average directions to the north, while JJA indicated directions to the south (N-S component). Longlived MCSs (i.e., MCS00 and MCS12) in MAM and JJA contributed more than short-lived MCSs, except for nighttime MCSs in JJA.

We obtained 24-hours accumulated occurrences of MCSs, average propagation speeds, and mean elevations in each longitude to represent features of MCSs propagated to the east. The research was original in that it removed dimensions to show features along with average elevations east of Rocky Mountains. Short-lived MCSs in MAM and JJA showed increasing average propagation speeds to the east - In contrast, long-lived MCSs in MAM and JJA indicated decreasing speeds to the east. Long-lived MCSs (i.e., MCS001 and MCS121) in MAM exhibited higher occurrences to the east, especially east of $96^{\circ} \mathrm{W}$ by showing peaks and fewer occurrences than long-lived MCSs in JJA. MCS12s in MAM and JJA showed similar distributions, while MCS00s in JJA exhibited higher occurrences than those in MAM.

This study's findings provide information to help researchers understand the differences in MCSs' longevity and initiation times, as well as a deeper understanding of features of long- and short-lived daytime and nighttime MCSs. The 
results can be used by forecasters and climate scientists to design experimental simulations for historical and future climates. A better understanding of MCS can be used as a proof of concept for experimental designs to develop and improve convection parameterization schemes. Finally, researchers will benefit from understanding the study's outcomes and limitations for warm-season climatology.

Acknowledgements The authors gratefully acknowledge support from the Global Water Future, Global Institute of Water Security at the University of Saskatchewan, Canada. This research was enabled in part by support provided by (Western Canada and West Grid) (https://www.westgrid.ca) and Compute Canada (www.computecanada.ca). Yanping Li acknowledges support from a Natural Sciences and Engineering Research Council of Canada (NSERC) Discovery Grant. We thank Andreas F. Prein for his pivotal contribution to provide Stage IV data.

\section{References}

Arritt RW, Rink TD, Segal M, Todey DP, Clark CA, Mitchell MJ, Labas KM (1997) The great plains low-level jet during the warm season of 1993. Monthly weather review 125(9):2176-2192

Ashley WS, Mote TL, Dixon PG, Trotter SL, Powell EJ, Durkee JD, Grundstein AJ (2003) Distribution of mesoscale convective complex rainfall in the united states. Monthly Weather Review 131(12):3003-3017

Cai H, Dumais Jr RE (2015) Object-based evaluation of a numerical weather prediction model's performance through forecast storm characteristic analysis. Weather and Forecasting 30(6):1451-1468

Carbone R, Tuttle J (2008) Rainfall occurrence in the us warm season: The diurnal cycle. Journal of Climate 21(16):4132-4146

Carbone R, Tuttle J, Ahijevych D, Trier S (2002) Inferences of predictability associated with warm season precipitation episodes. Journal of the Atmospheric Sciences 59(13):2033-2056

Coniglio MC, Corfidi S (2006) Forecasting the speed and longevity of severe mesoscale convective systems. In: Symposium on the Challenges of Severe Convective Storms

Corfidi SF (2003) Cold pools and mcs propagation: Forecasting the motion of downwind-developing mcss. Weather and forecasting 18(6):997-1017

Evans JS, Doswell CA (2001) Examination of derecho environments using proximity soundings. Weather and Forecasting 16(3):329-342

Feng Z, Leung LR, Hagos S, Houze RA, Burleyson CD, Balaguru K (2016) More frequent intense and long-lived storms dominate the springtime trend in central us rainfall. Nature Communications 7(1):1-8

Feng Z, Houze RA, Leung LR, Song F, Hardin JC, Wang J, Gustafson WI, Homeyer CR (2019) Spatiotemporal characteristics and large-scale environments of mesoscale convective systems east of the rocky mountains. Journal of Climate 32(21):7303-7328

Fritsch J, Kane R, Chelius C (1986) The contribution of mesoscale convective weather systems to the warm-season precipitation in the united states. Journal of Applied Meteorology and Climatology 25(10):1333-1345

Geerts B, Parsons D, Ziegler CL, Weckwerth TM, Biggerstaff MI, Clark RD, Coniglio MC, Demoz BB, Ferrare RA, Gallus Jr WA, et al. (2017) The 2015 
plains elevated convection at night field project. Bulletin of the American Meteorological Society 98(4):767-786

Glickman TS (2000) Glossary of Meteorology, 2nd edn. American Meteorological Society

Grabowski W, Bechtold P, Cheng A, Forbes R, Halliwell C, Khairoutdinov M, Lang S, Nasuno T, Petch J, Tao WK, et al. (2006) Daytime convective development over land: A model intercomparison based on lba observations. Quarterly Journal of the Royal Meteorological Society: A journal of the atmospheric sciences, applied meteorology and physical oceanography 132(615):317-344

Haberlie AM, Ashley WS (2019) A radar-based climatology of mesoscale convective systems in the united states. Journal of Climate 32(5):1591-1606

Heideman KF, Michael Fritsch J (1988) Forcing mechanisms and other characteristics of significant summertime precipitation. Weather and forecasting 3(2):115130

Houze R (1993) Cloud dynamics, 573 pp. Academic, San Diego, Calif

Houze Jr RA, Smull BF, Dodge P (1990) Mesoscale organization of springtime rainstorms in oklahoma. Monthly Weather Review 118(3):613-654

Jirak IL, Cotton WR (2007) Observational analysis of the predictability of mesoscale convective systems. Weather and Forecasting 22(4):813-838

Jirak IL, Cotton WR, McAnelly RL (2003) Satellite and radar survey of mesoscale convective system development. Monthly weather review 131(10):2428-2449

Laing AG, Fritsch JM (2000) The large-scale environments of the global populations of mesoscale convective complexes. Monthly Weather Review 128(8):27562776

Li Y, Smith RB (2010) The detection and significance of diurnal pressure and potential vorticity anomalies east of the rockies. Journal of the Atmospheric Sciences 67(9):2734-2751

Maddox RA (1980) Mesoscale convective complexes. Bulletin of the American Meteorological Society pp 1374-1387

Nelson BR, Prat OP, Seo DJ, Habib E (2016) Assessment and implications of ncep stage iv quantitative precipitation estimates for product intercomparisons. Weather and Forecasting 31(2):371-394

Prein AF, Liu C, Ikeda K, Bullock R, Rasmussen RM, Holland GJ, Clark M (2017) Simulating north american mesoscale convective systems with a convectionpermitting climate model. Climate Dynamics pp 1-16

$\mathrm{Pu}$ B, Dickinson RE (2014) Diurnal spatial variability of great plains summer precipitation related to the dynamics of the low-level jet. Journal of the Atmospheric Sciences 71(5):1807-1817

Scaff L, Prein AF, Li Y, Liu C, Rasmussen R, Ikeda K (2019) Simulating the convective precipitation diurnal cycle in north america's current and future climate. Climate Dynamics pp 1-14

Song F, Feng Z, Leung LR, Houze Jr RA, Wang J, Hardin J, Homeyer CR (2019) Contrasting spring and summer large-scale environments associated with mesoscale convective systems over the us great plains. Journal of Climate $32(20): 6749-6767$

Trapp RJ, Weisman ML (2003) Low-level mesovortices within squall lines and bow echoes. part ii: Their genesis and implications. Monthly weather review 131(11):2804-2823 
Trier S, Davis C, Ahijevych D (2010) Environmental controls on the simulated diurnal cycle of warm-season precipitation in the continental united states. Journal of the atmospheric sciences 67(4):1066-1090

Tripoli GJ, Cotton WR (1989a) Numerical study of an observed orogenic mesoscale convective system. part 1: Simulated genesis and comparison with observations. Monthly Weather Review 117(2):273-304

Tripoli GJ, Cotton WR (1989b) Numerical study of an observed orogenic mesoscale convective system. part 2: Analysis of governing dynamics. Monthly weather review 117(2):305-328

Tuttle JD, Davis CA (2006) Corridors of warm season precipitation in the central united states. Monthly Weather Review 134(9):2297-2317

Walters CK, Winkler JA, Shadbolt RP, van Ravensway J, Bierly GD (2008) A long-term climatology of southerly and northerly low-level jets for the central united states. Annals of the Association of American Geographers 98(3):521-552 
The analysis domain

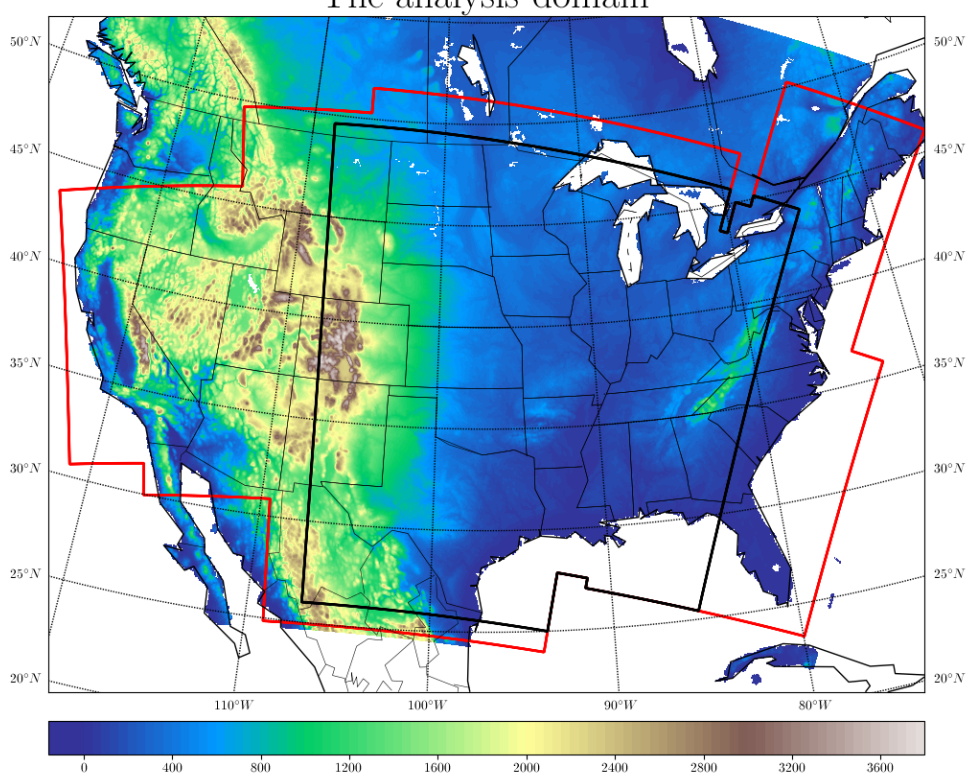

Fig. 1 National Weather Service(NWS) River Forecast Center(RFC) domains as translated to Stage IV the national Hydrologic Rainfall Analysis Projection(HRAP) grid, from (Nelson et al., 2016). The coverage of Stage IV (superimposed as red contours), and the analysis region of this study (highlighted with a black rectangle) are represented. 

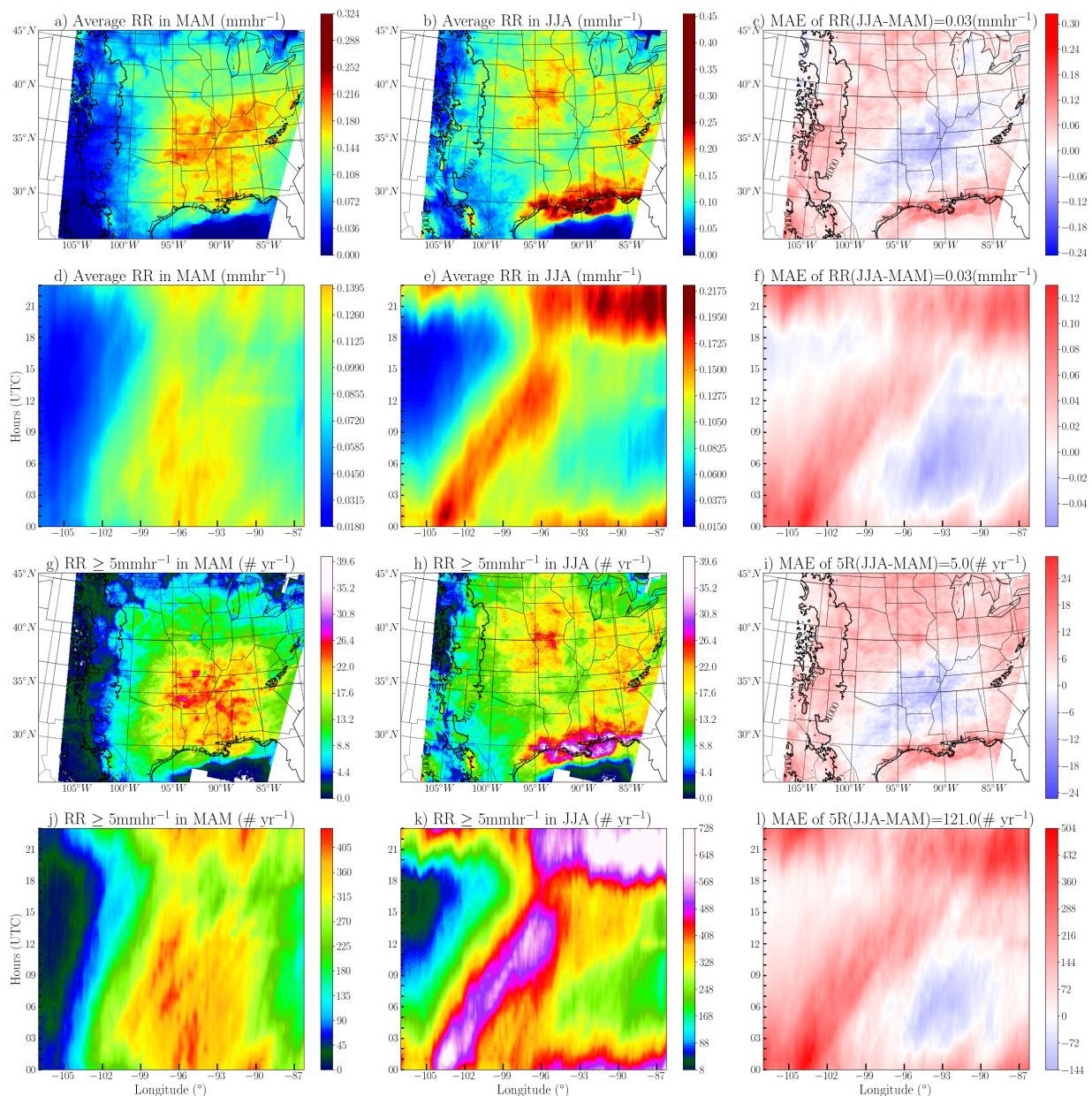

Fig. 2 Average rain rates $\left(\mathrm{mmhr}^{-1}\right)$ in a) spring (MAM), b) summer (JJA), c) differences between spring and summer, Hovmoller diagrams d) MAM, e) JJA, and f) JJA-MAM. Rain rates over $5 \mathrm{mmhr}^{-1}$ are represented as g) to i) and in Hovmoller diagrams as j) to l). The summation of absolute differences is represented as numbers in titles in e), f), i), and l). 

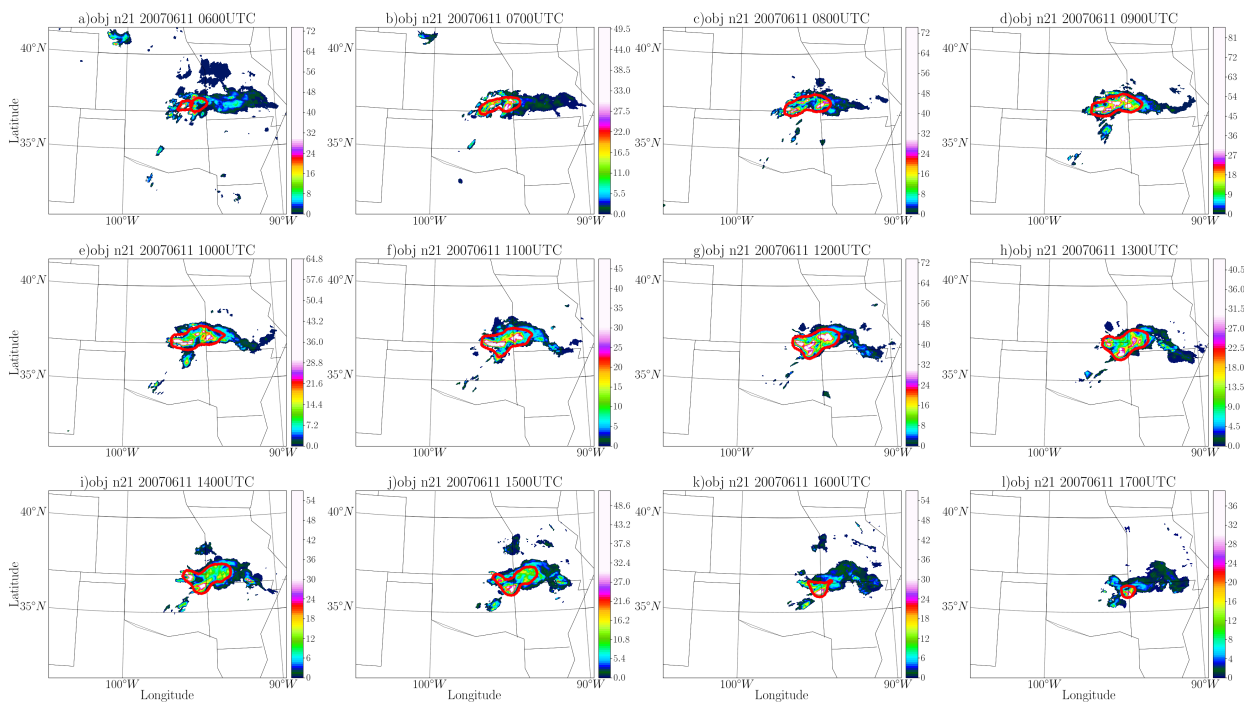

Fig. 3 Examples of hourly MTD-determined MCSs from 0600 to 1700 UTC 11 June 2007. Red contours indicate the objects that were MTD-determined events. 

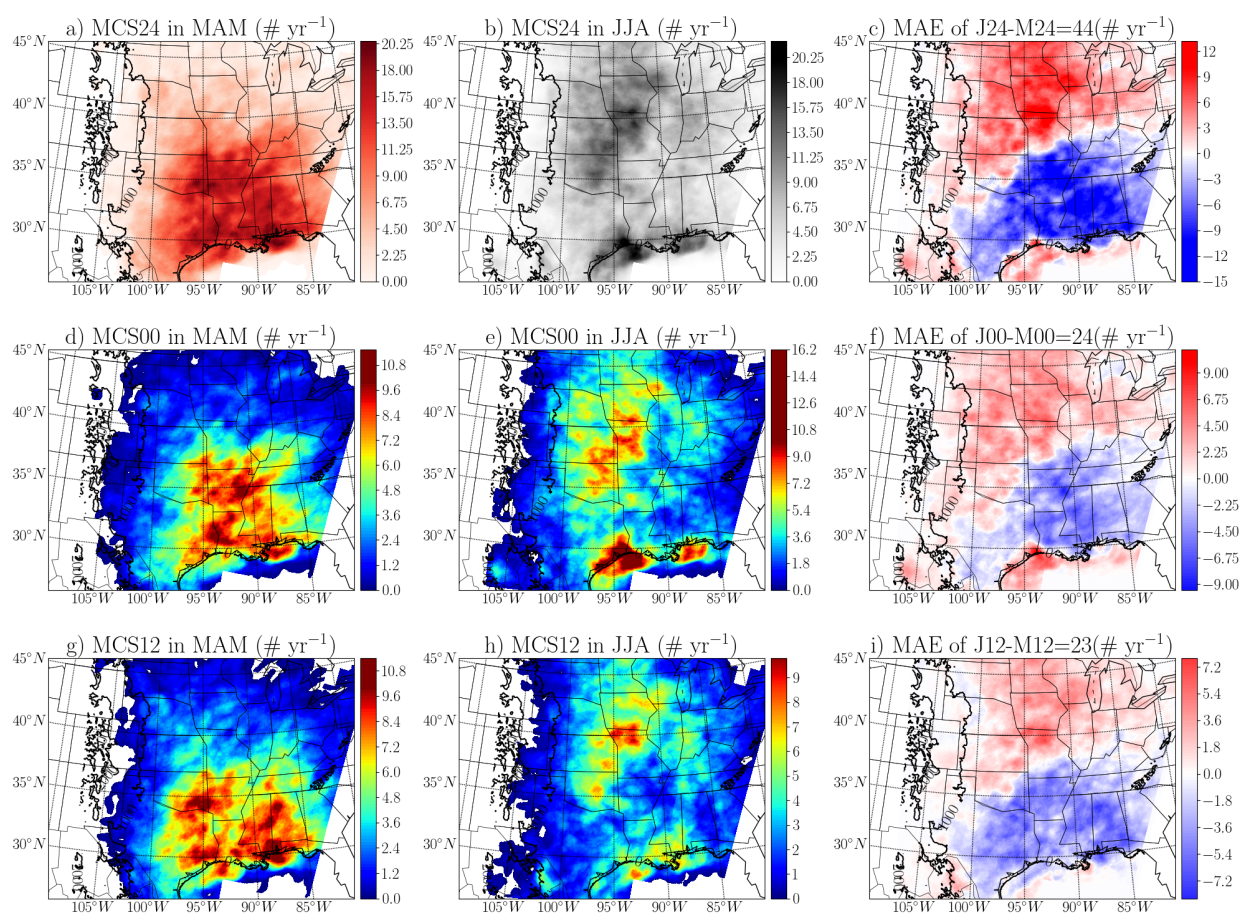

Fig. 4 The occurrences of MTD-determined MCSs (MCS24) in a) MAM, b) JJA, and c) differences between spring and summer (JJA-MAM). The occurrences are further divided into nighttime MCSs (MCSO0) in d) MAM, e) JJA, and f) differences between d) and e) and daytime MCSs (MCS12) in g) MAM, h) MAM, and i) differences of g) and h). 


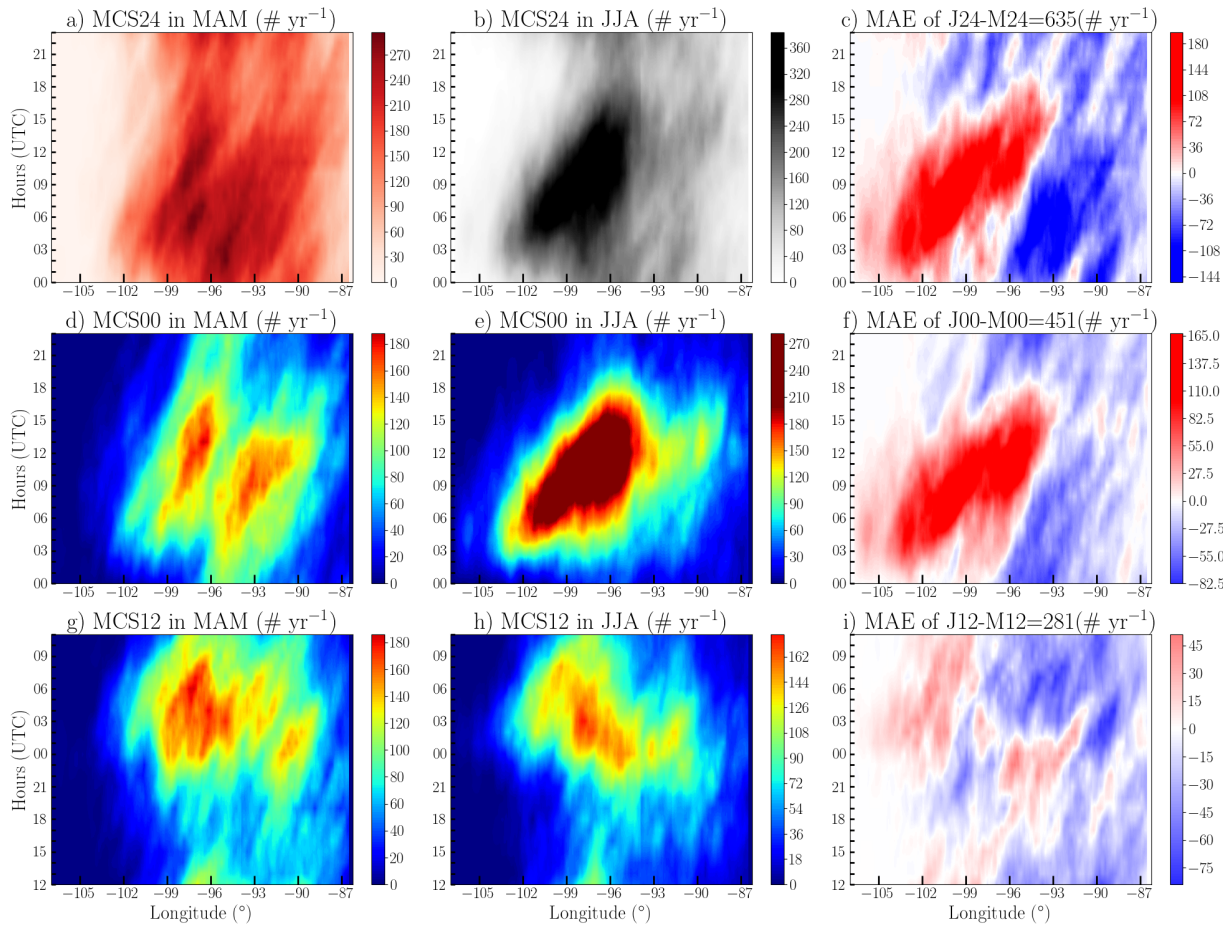

Fig. 5 As in Fig. 4, but represented in Hovmoller diagrams. Note that y-axes of a) to f) start from $00 \mathrm{UTC}$ and $\mathrm{g}$ ) to i) from $12 \mathrm{UTC}$. 
a) $\operatorname{MCS} 00$ (count)

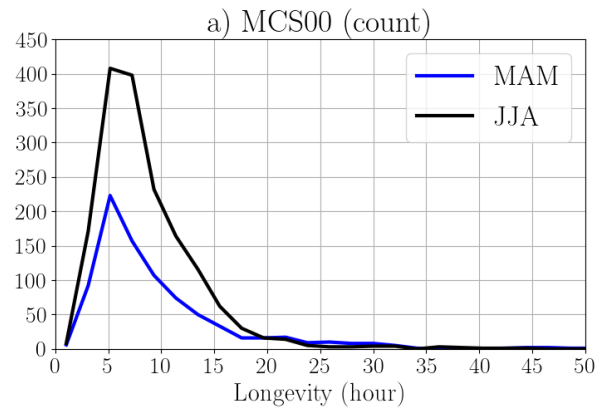

c) MCS00 coverage $\left(\mathrm{km}^{2}\right)$

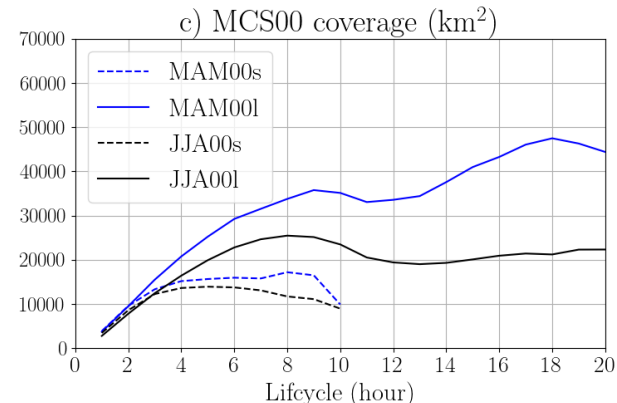

e) MCSO0 speed $\left(\mathrm{ms}^{-1}\right)$

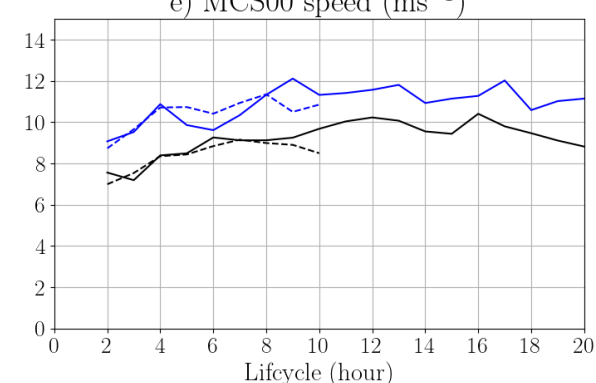

g) MCS00 E-W $\left(\mathrm{ms}^{-1}\right)$

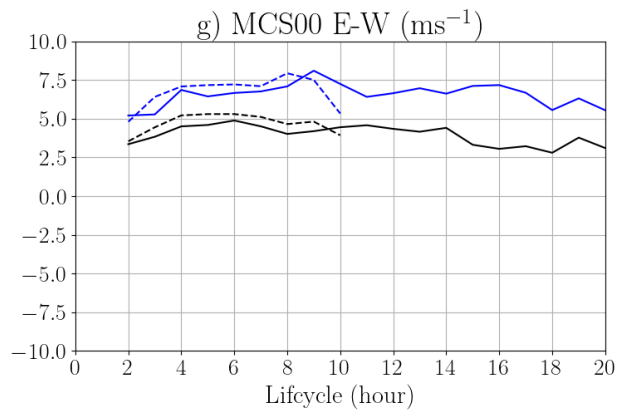

i) MCS00 N-S $\left(\mathrm{ms}^{-1}\right)$

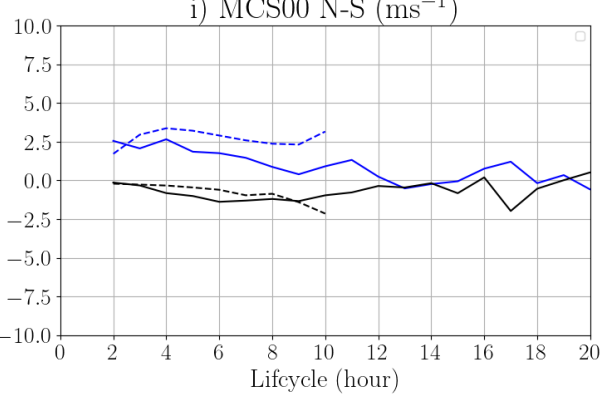

b) MCS12 (count)

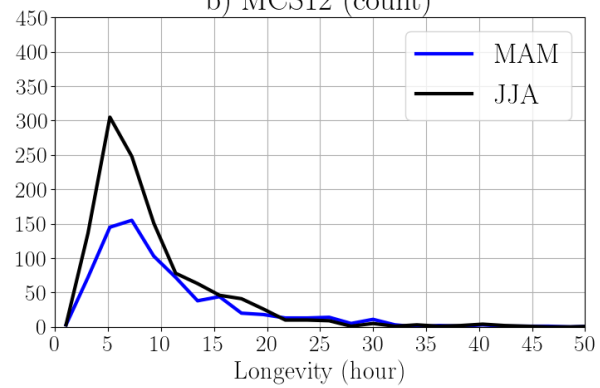

d) MCS12 coverage $\left(\mathrm{km}^{2}\right)$

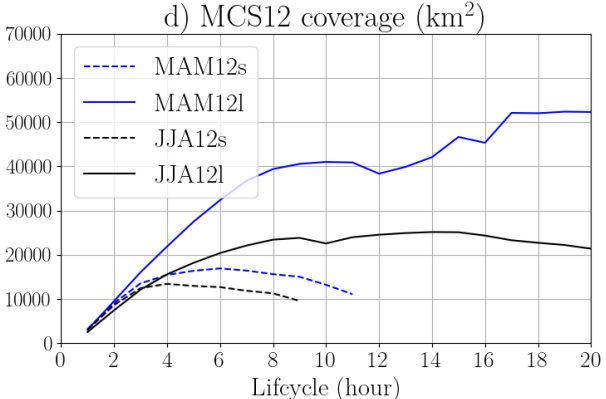

f) MCS 12 speed $\left(\mathrm{ms}^{-1}\right)$

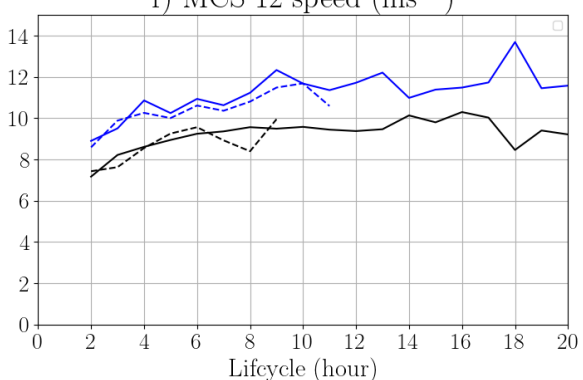

h) MCS12 E-W $\left(\mathrm{ms}^{-1}\right)$

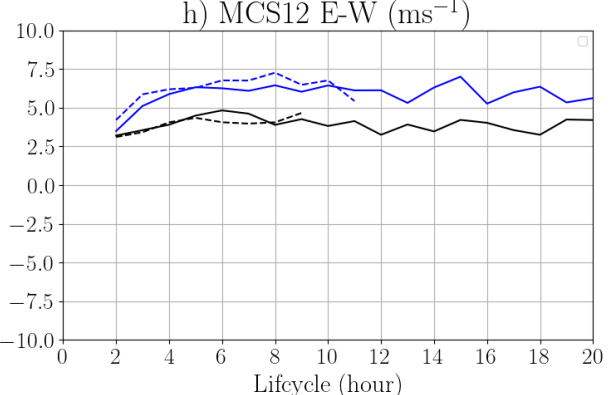

j) $\mathrm{MCS} 12 \mathrm{~N}-\mathrm{S}\left(\mathrm{ms}^{-1}\right)$

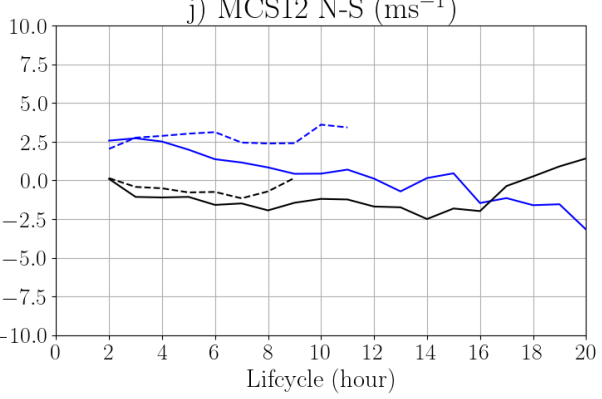

Fig. 6 Statistics of longevities of a) nighttime MCSs (MCS00) and b) daytime MCSs (MCS12). The average values are represented as life cycles of MCS as areal coverages c) MCS00 and d) MCS12, propagation speeds e) MCS00 and f) MCS12, E-W component of propagation speeds of g) MCS00 and h) MCS12, and N-S component of propagation speeds i) MCS00 and j) MCS12. 

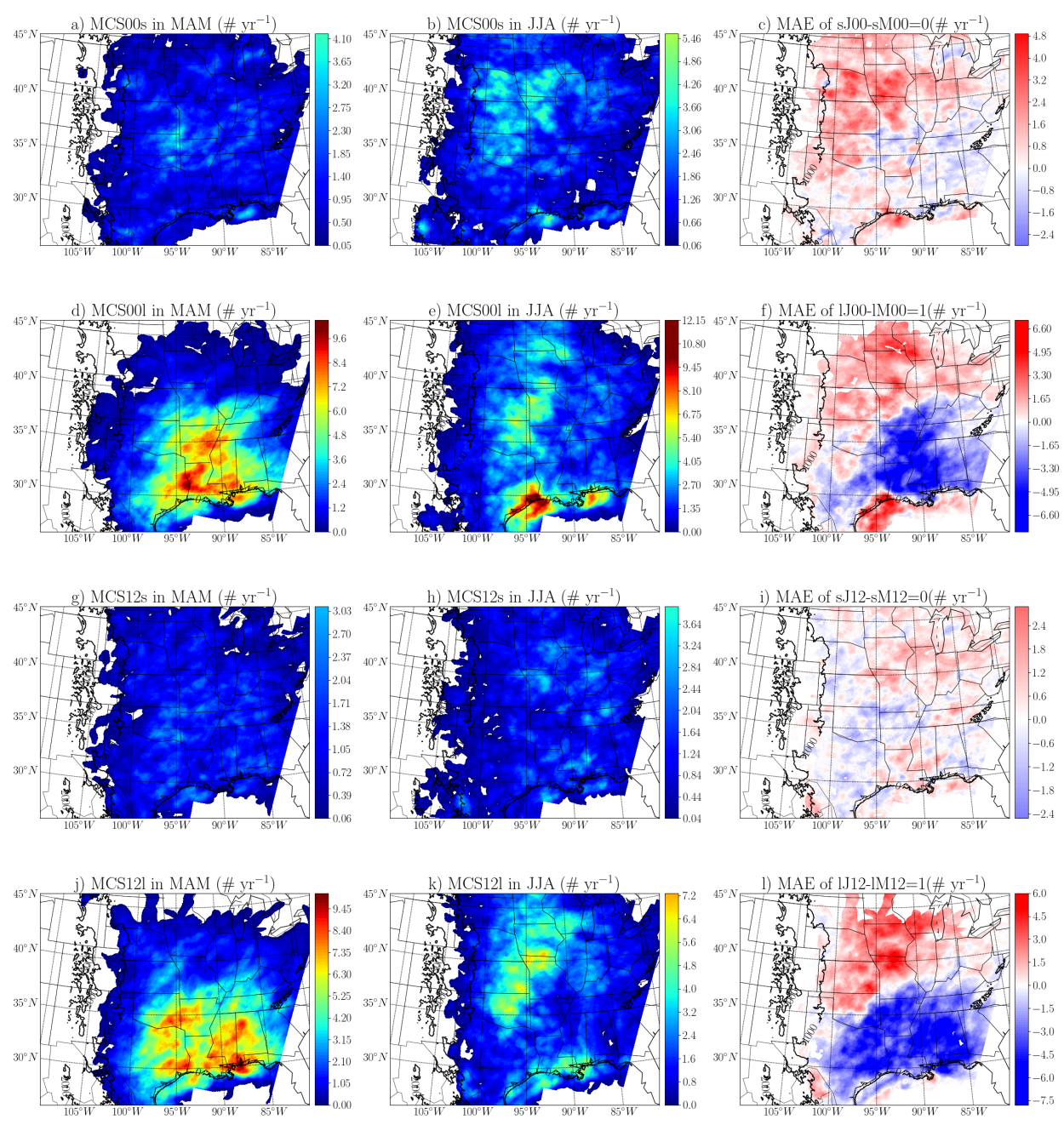

Fig. 7 The occurrences of MTD-determined MCSs of short-lived nighttime MCSs (MCS00s) in a) MAM, b) JJA, and c) differences between a) and b). Occurrences of d) to f) long-lived nighttime MCSs (MCS00l), g) to i) short-lived daytime MCSs (MCS12s), and j) to l) long-lived daytime MCSs (MCS12l). 

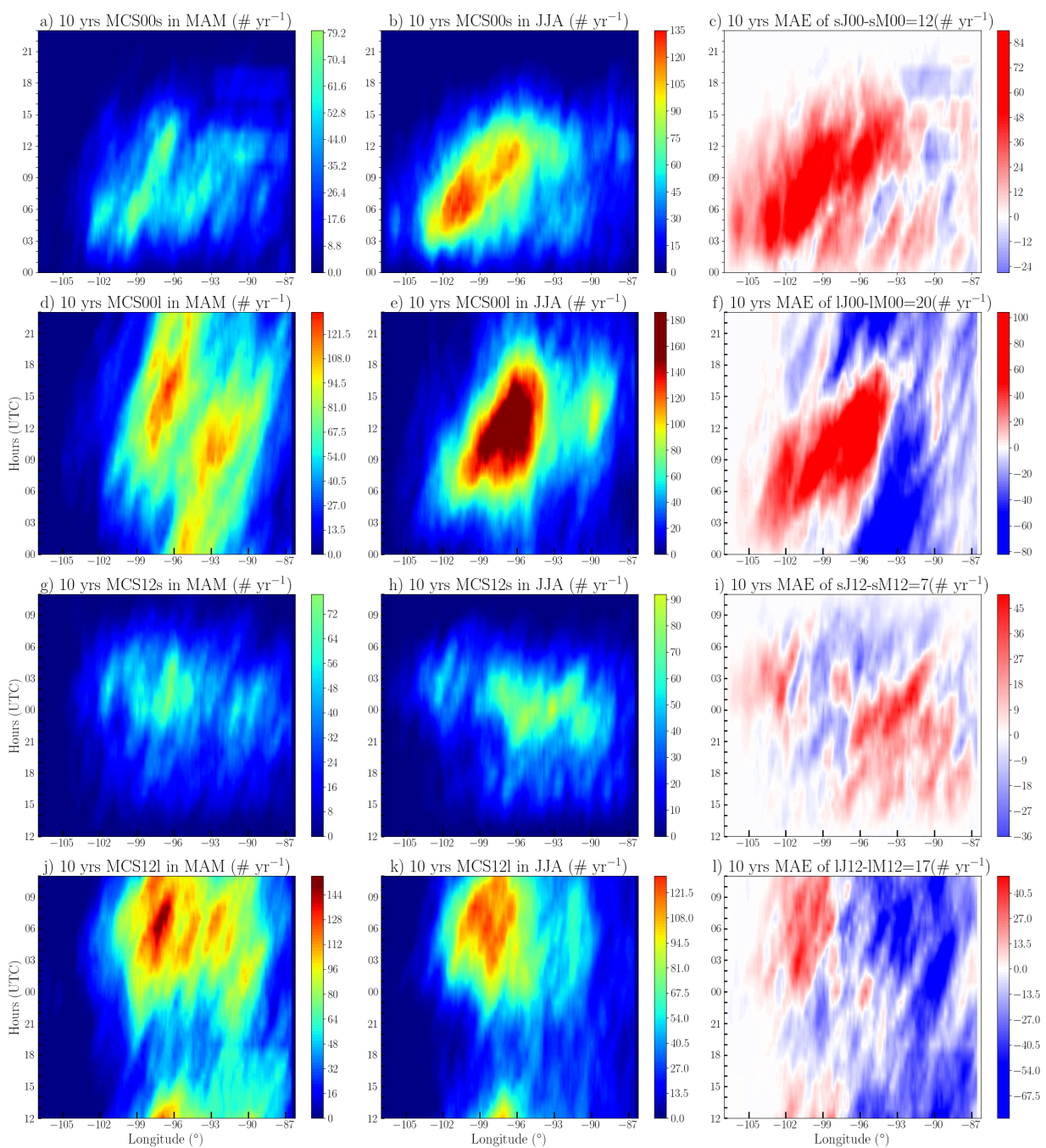

Fig. 8 As in Fig. 7, but represented in Hovmoller diagrams. Note that y-axes of a) to f) start from 00 UTC and g) to i) from 12 UTC. 

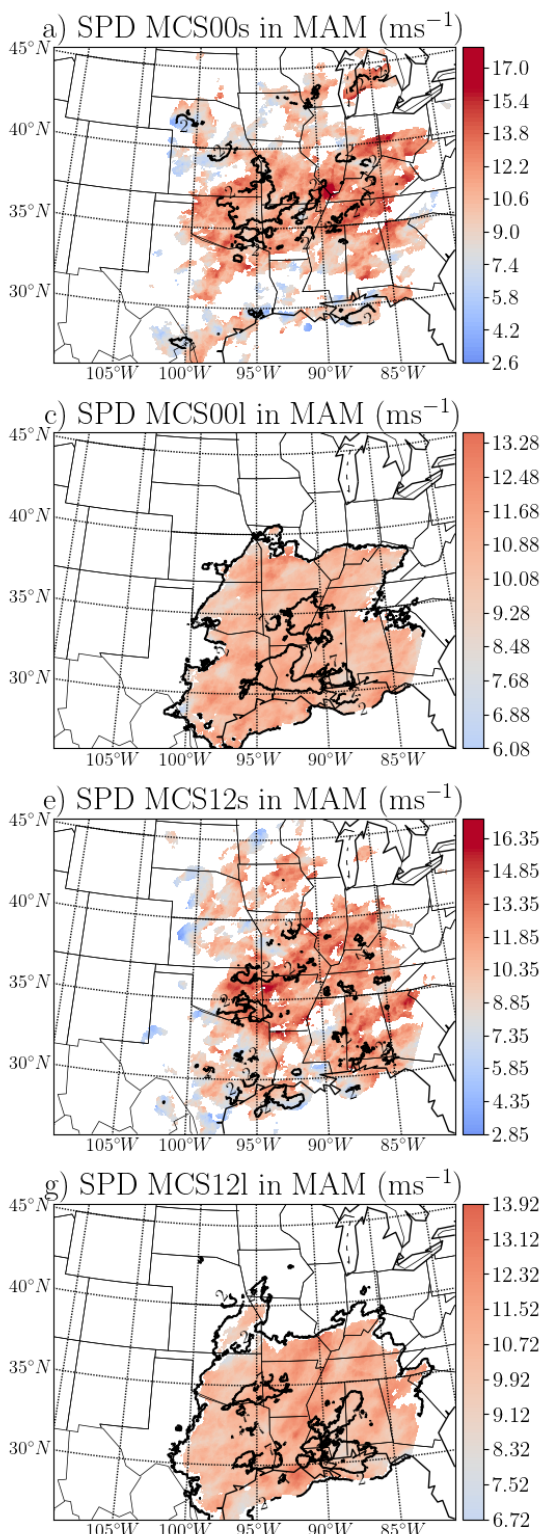
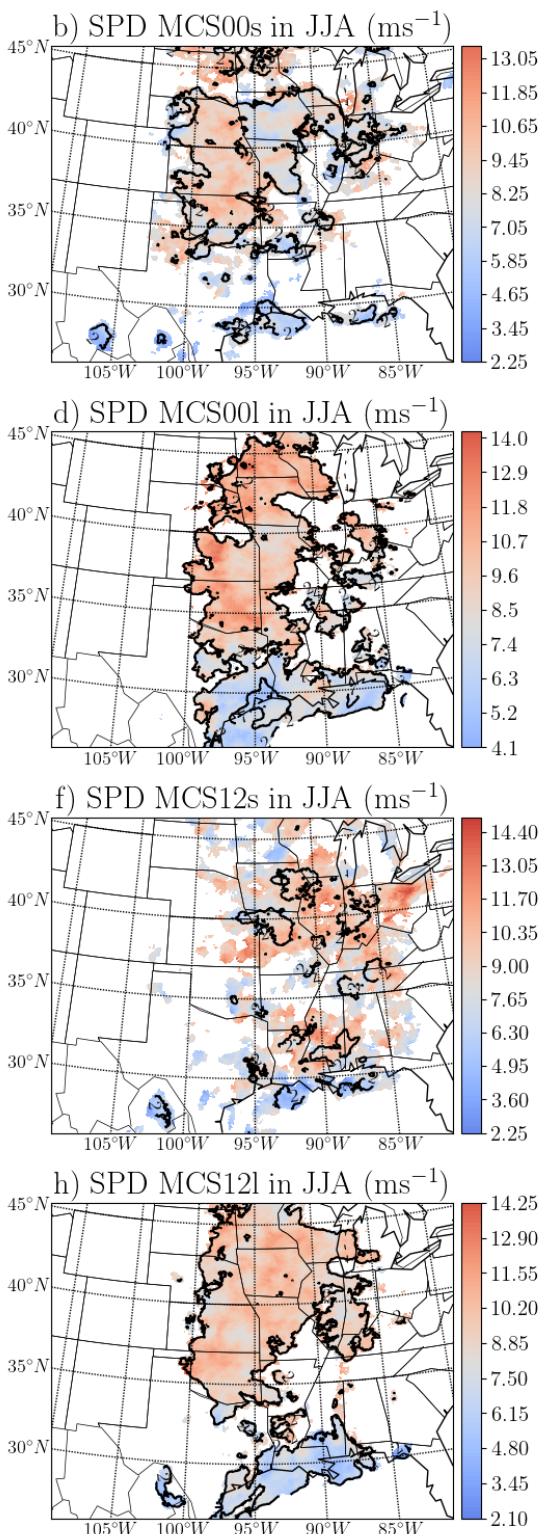

Fig. 9 The average propagation speeds of MTD-determined short-lived nighttime MCSs (MCS00s) in a) MAM, b) JJA. Average propagation speeds of c) and d) long-lived nighttime MCSs (MCS001), e) and f) short-lived daytime MCSs (MCS12s), and g) and h) long-lived daytime MCSs (MCS121). Occurrences of MCSs are superimposed as black contours from 20 to 70 counts. 

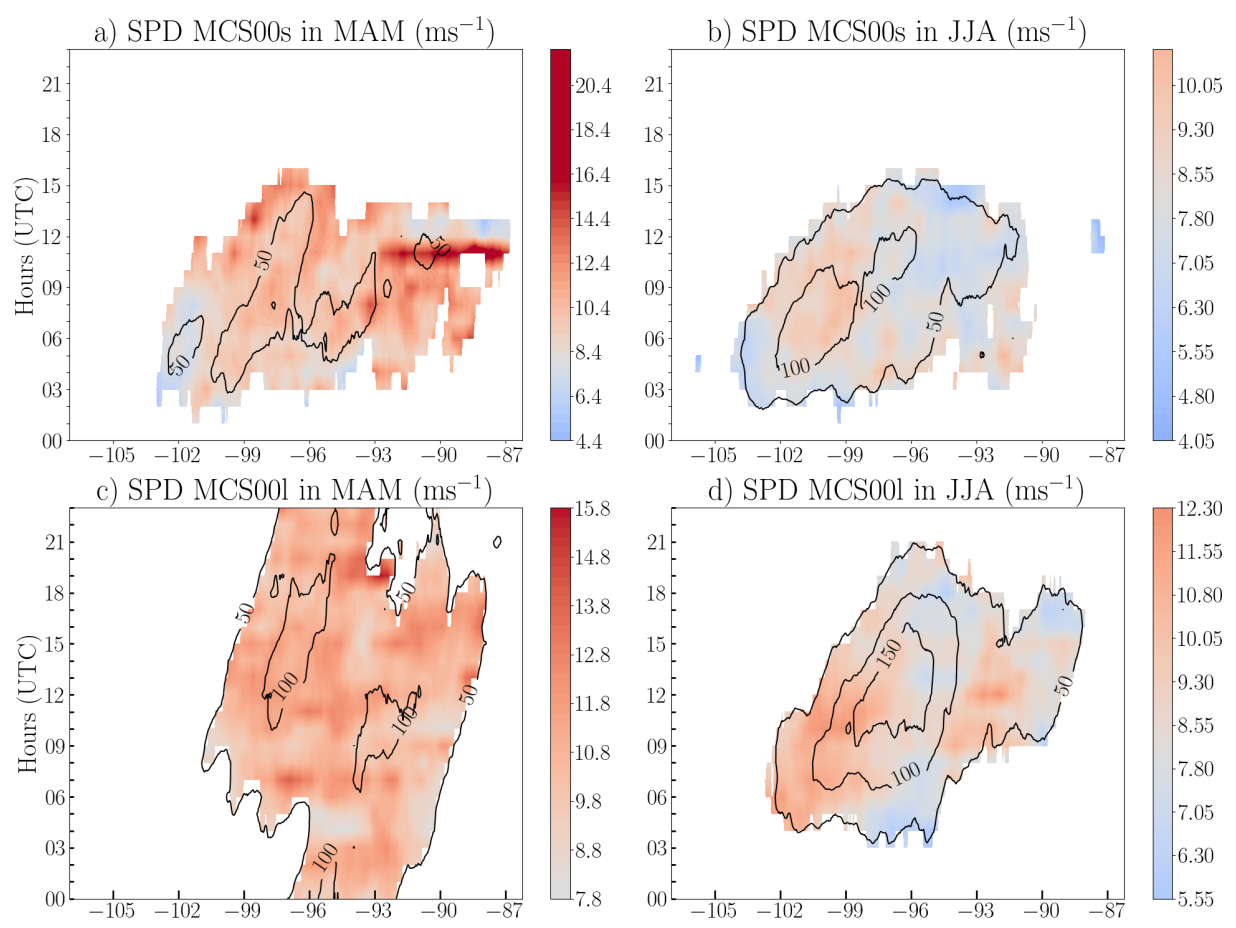

d) SPD MCS00l in JJA $\left(\mathrm{ms}^{-1}\right)$

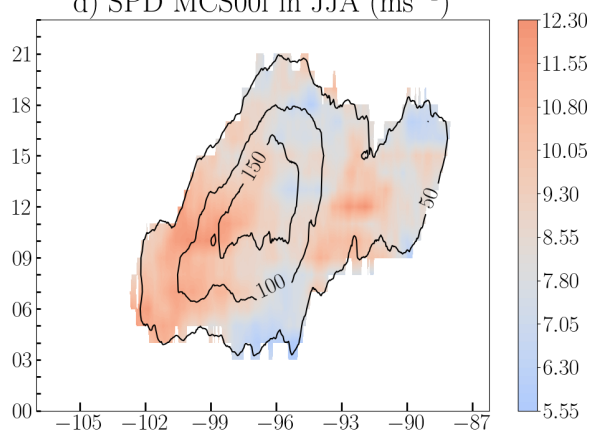

e) SPD MCS12s in MAM $\left(\mathrm{ms}^{-1}\right)$
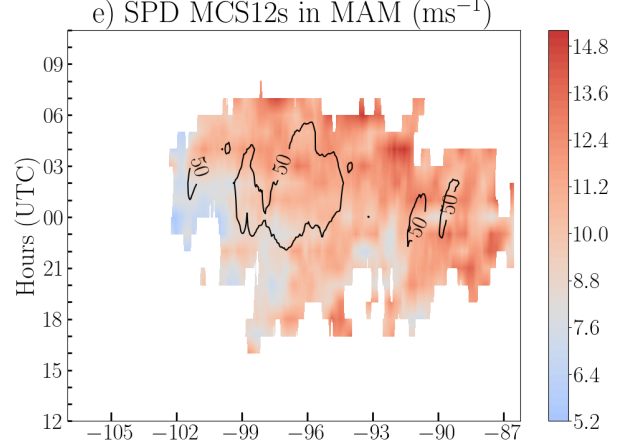

f) SPD MCS12s in JJA $\left(\mathrm{ms}^{-1}\right)$
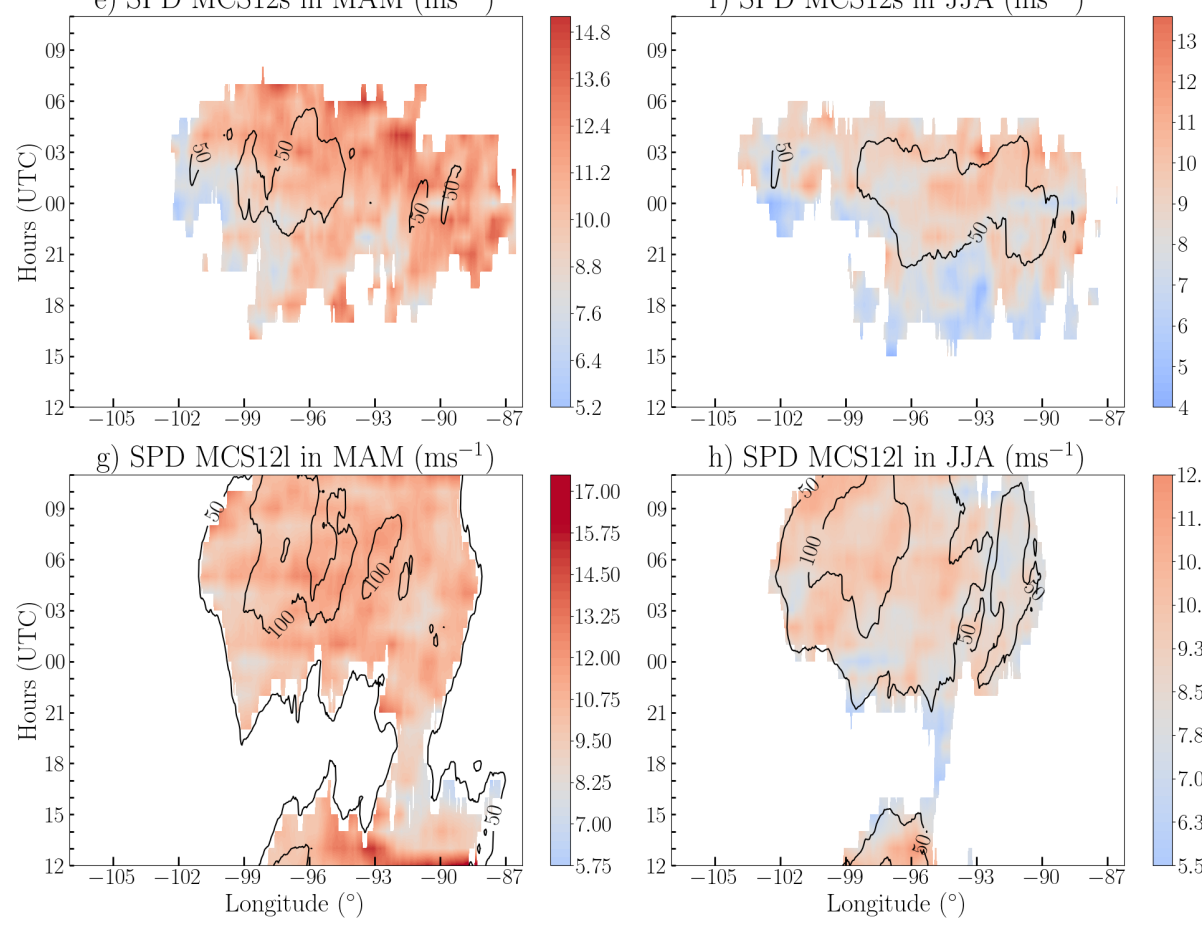

h) SPD MCS12l in JJA $\left(\mathrm{ms}^{-1}\right)$

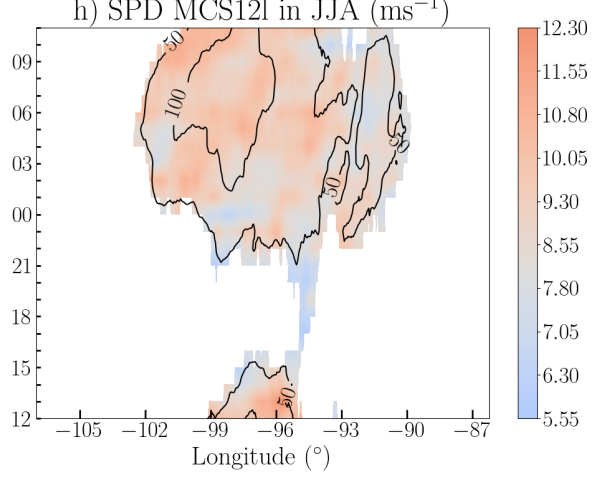

Fig. 10 As in Fig. 9, but represented in Hovmoller diagrams. Note that y-axes of a) to d) start from 00 UTC and e) to h) from 12 UTC. Occurrences of MCSs are superimposed as black contours from 50 to 150 counts 

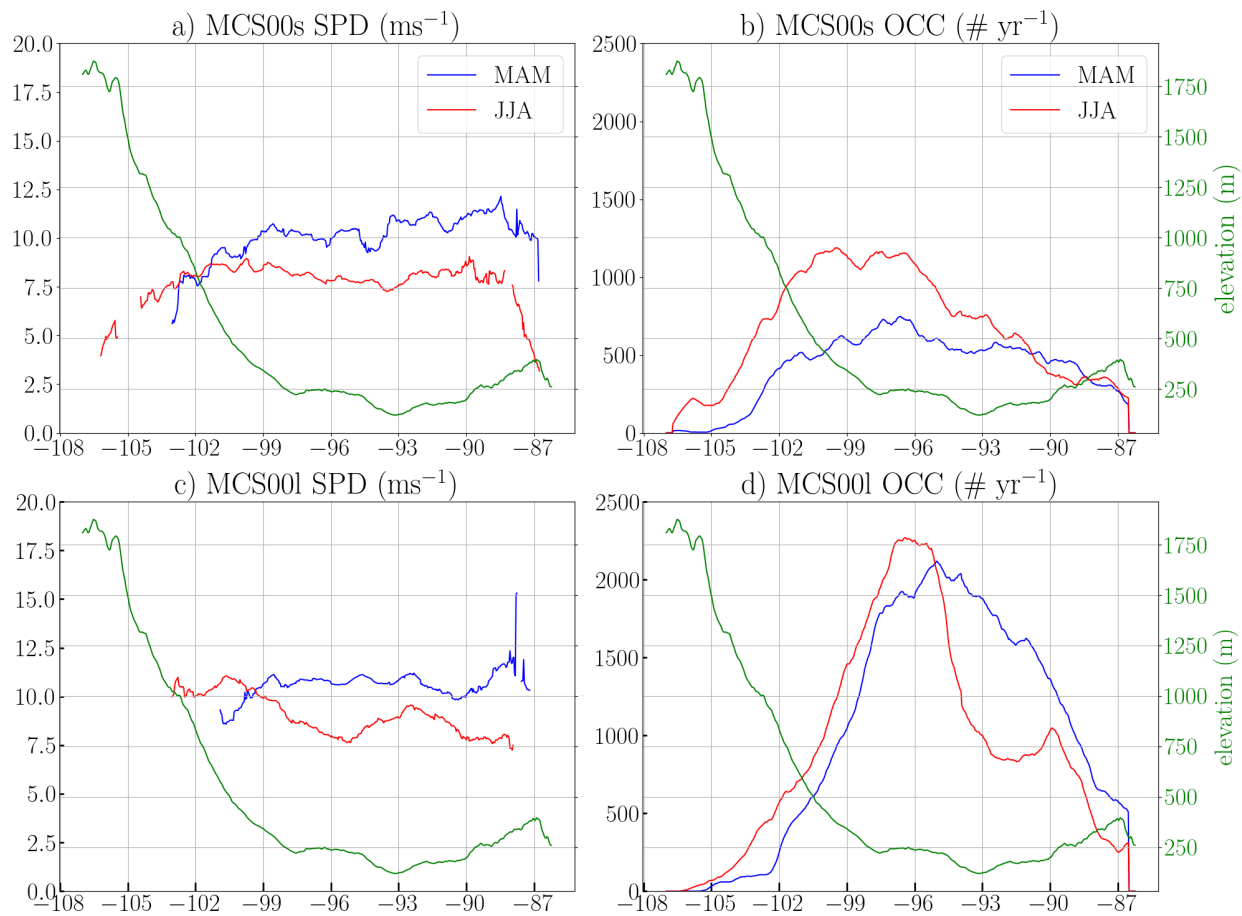

d) MCS001 OCC $\left(\# \mathrm{yr}^{-1}\right)$
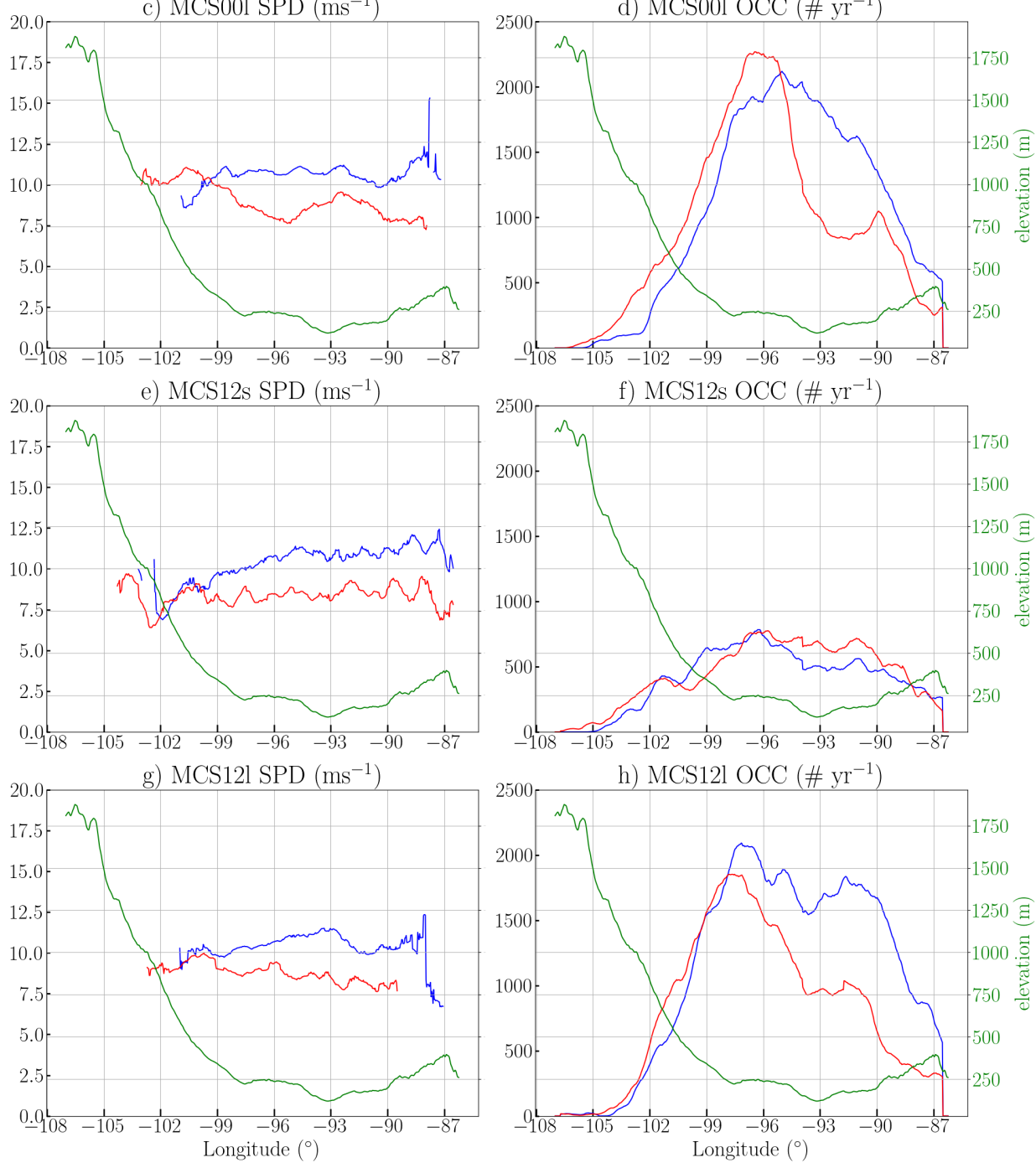

Fig. 11 The average propagation speeds (SPD) and summation of occurrences (OCC) of short-lived nighttime MCSs (MCS00s) are shown in a) and b). Average propagation speeds and summation of occurrences from c) to d) long-lived nighttime MCSs (MCS001), e) to f) short-lived daytime MCSs (MCS12s), and g) to h) long-lived daytime MCSs (MCS12l). Results for MAM are shown in blue lines and those for JJA are shown in red lines. 